\title{
Article \\ DETECTING TROPICAL FOREST DEGRADATION USING OPTICAL SATELLITE DATA: AN EXPERIMENT IN PERU SHOW TEXTURE AT 3 M GIVES BEST RESULTS
}

\author{
Chiara Aquino $^{1} \mathbb{D}^{*}$, Edward T. A. Mitchard ${ }^{1} \mathbb{D}$, Iain M. McNicol ${ }^{1} \mathbb{D}$, Harry Carstairs ${ }^{1} \mathbb{D}$, Andrew Burt ${ }^{\mathbb{D}}$, Beisit Luz \\ Puma Vilca $^{3}$, Sylvia Mayta ${ }^{3}(\mathbb{D})$ and Mathias Disney ${ }^{2}(\mathbb{D}$ \\ 1 School of Geosciences, University of Edinburgh, Crew Building, King's Buildings, Alexander Crum Brown \\ Road, Edinburgh EH9 3FF, UK \\ 2 Department of Geography, University College London, Gower Street, London WC1E 6BT, UK \\ 3 Escuela Profesional de Biología, Universidad Nacional de San Antonio Abad del Cusco, Av. La cultura 773, \\ Cusco, Perú \\ 4 Asociación para la Investigación y Desarrollo Integral, Calle Las Camelias 174, Piso 6, San Isidro, Lima, \\ Perú \\ * Correspondence: chiara.aquino@ed.ac.uk
}

\begin{abstract}
Forest degradation is known to be widespread in the tropics, but is currently very poorly mapped, in part because there is little quantitative data on which satellite sensor characteristics and analysis methods are best at detecting it. To improve this, we used data from the Tropical Forest Degradation Experiment (FODEX) plots in the southern Peruvian Amazon, where different numbers of trees had been removed from four 1 ha forest plots, carefully inventoried by hand and Terrestrial Laser Scanning before and after the logging to give a range of biomass change ( $\triangle \mathrm{AGB}$ ) values. We conducted a comparative study of six multispectral optical satellite sensors (WorldView3, SkySat, SPOT-7, PlanetScope, Sentinel-2 and Landsat 8) at $0.3-30 \mathrm{~m}$ spatial resolution, to find the best combination of sensor and remote sensing indicator for change detection. Spectral reflectance, the Normalized Difference Vegetation Index (NDVI) and texture parameters were extracted after radiometric calibration and image preprocessing. The strength of the relationships between the change in these values and field-measured $\triangle \mathrm{AGB}$ (computed in $\% \mathrm{ha}^{-1}$ ) was analysed. The results demonstrate that: (a) texture measures correlates more with $\triangle \mathrm{AGB}$ than simple spectral parameters; (b) the strongest correlations are achieved for those sensors with spatial resolutions in the intermediate range $(1.5-10 \mathrm{~m})$, with finer or coarser resolutions producing worse results, and (c) when texture is computed using a moving square window ranging between $9-14 \mathrm{~m}$ in length. Maps predicting $\triangle$ AGB showed very promising results using a NIR-derived texture parameter for $3 \mathrm{~m}$ resolution PlanetScope $\left(\mathrm{R}^{2}=0.97\right.$ and RMSE $\left.=1.80 \% \mathrm{ha}^{-1}\right)$, followed by 1.5 $\mathrm{m}$ SPOT-7 $\left(\mathrm{R}^{2}=0.74\right.$ and RMSE $\left.=5.25 \% \mathrm{ha}^{-1}\right)$ and $10 \mathrm{~m}$ Sentinel- $2\left(\mathrm{R}^{2}=0.71\right.$ and RMSE $=5.55$ $\% \mathrm{ha}^{-1}$ ). Texture models derived from $0.3 \mathrm{~m}$ WorldView- 3 improved with increasing window size, with highest $R^{2}$ of 0.62 and RMSE $=6.35 \% \mathrm{ha}^{-1}$ for a window of $14 \mathrm{~m}$ in length. The degradation in our field plots is invisible to the $30 \mathrm{~m}$ resolution Landsat data. Our findings imply that, at least for lowland Peru, low-medium intensity disturbance can be detected best in optical wavelengths using a texture measure derived from $3 \mathrm{~m}$ PlanetScope data. That such data are being collected daily, and currently released free as monthly mosaics over tropical forests as part of the Norway's International Climate and Forest Initiative (NICFI), is excellent news for monitoring such degradation.
\end{abstract}

Keywords: forest degradation, biomass change, texture analysis, NDVI, Earth Observation, Satellite Data, PlanetScope, WorldView-3, Sentinel-2, Landsat, SkySat, SPOT 


\section{Introduction}

Tropical forests play a complex and essential role in modulating the global climate system by removing carbon dioxide from the atmosphere through photosynthesis. They are home to a rich biodiversity and provide an essential source of livelihood and sociocultural identity to local communities. However, pressures from extractive industries, commodity-driven agricultural expansion and fires are increasingly threatening the integrity of these forests $[1,2]$. As a result of factors such as deforestation, forest degradation and climate change, the ability of tropical forests to sequester atmospheric carbon might be reduced or reversed in the near future [3,4]

Contrary to deforestation, which occurs when a forest has sufficient trees removed that it no longer meets the local definition of forest [5], degradation is harder to define [6]. In general, forest degradation is considered to occur when humans cause partial deforestation, with more than $10-30 \%$ of forest cover remaining [7]. Half of tropical forest degradation is thought to be driven by selective logging, followed by fuelwood and charcoal production, fires and livestock grazing [8]. Studies aiming at quantifying the carbon emissions and extent of degradation show that it is diffuse across the tropics and affects land portions similar to, or even larger, than deforestation [9,10]. Since degradation precedes deforestation, controlling the former may prevent the development of the latter [6]. Monitoring forest degradation while protecting existing old-growth, natural forests, has longer term climate and ecological benefits than planting new trees [10-14], typically when forest lands are managed collectively [15-19] and the social drivers of deforestation are addressed [20]. It is worth noting that the monitoring effort should not imply the commodification of carbon stocks [21,22]. An abundant literature has shown that market-based mechanisms reinforce exclusionary politics, such as the centralization of forest tenure and the exclusion of certain actors, practices, knowledge and claims to resources [23-27], which in turn exacerbates forest loss [25,28]. Addressing deforestation and forest degradation requires trade-offs between economic, ecological and social dimensions [29] and the recognition of the political and power dimensions behind the interventions; an aspect that carbon finance, with its unidimensional approach to forest management, tends to overlook, to the detriment of forests and forest-dependent communities [30].

While it has been possible to map deforestation even with moderate resolution (30 $250 \mathrm{~m}$ ) satellite imagery [31,32], disturbances at finer scales, as those caused by selective logging or other degradation processes, remain challenging to detect [2]. High resolution optical data (e.g., WorldView-3) are cost prohibitive and are not always immediately available in all regions. On the other hand, Synthetic Aperture Radar (SAR) systems do not perform well in dense canopies due to biomass saturation effects [33]. Airborne LiDAR has now gained widespread adoption in forestry applications because of its ability to produce 3D point clouds with centimeter accuracy [34,35]. However, LiDAR collection campaigns are very expensive and data availability is drastically limited in space and time [36].

In the last decade, the progressive release of remote sensing data that is both temporally dense and high-resolution $(\leq 10 \mathrm{~m})$ has opened new frontiers for mapping and monitoring changes in forest cover in usually remote and inaccessible areas. The use of dense time series to detect forest disturbance events is particularly important in the tropics, as rapid vegetation turnover can remove the transient signs of the disturbance events rapidly [37], and cloud cover often masks images, meaning that many attempts may be necessary before the trees are seen from space. Freely available, high-resolution optical multispectral imagery from the European Space Agency (ESA)'s Sentinel-2 mission and the monthly PlanetScope image mosaics (available across tropical forest areas only [38]) allow for unprecedented monitoring of forest loss at frequent time intervals and at minimum costs. While these satellite datasets are at a 3-4 $\mathrm{m}$ and $10 \mathrm{~m}$ resolution respectively, commercial satellite data at higher resolutions (up to $0.3 \mathrm{~m}$ ) are available on request, and there remains a long archive of $30 \mathrm{~m}$ resolution Landsat imagery which, 
if suitable for mapping degradation, would open up a long and consistent record of forest disturbance. However, it is unclear which of these datasets, if any, is suitable for mapping forest degradation. Hence, there is an increasing necessity of matching satellite observations against ground truth data, showing the exact magnitude and location of forest loss and thus reducing the critical uncertainties in biomass change estimates [39].

The Normalized Difference Vegetation Index (NDVI) is one of the most widely used indices for estimating tree aboveground biomass (AGB). NDVI is computed from the ratio of the near-infrared (NIR) and red spectral bands. For healthy vegetation, the presence of chlorophyll pigments causes a strong absorption in the red band, while the internal leaf structure results in high reflectivity in the NIR. Therefore, healthy, dense canopy cover tends to have a high NDVI value, while degradation of ecosystem vegetation such that trunks, branches or the soil can be seen, or a decrease in the density of green vegetation, would result in lower NDVI [40,41]. Unfortunately, NDVI saturates in regions of high forest biomass, partially due to the low penetration capability of the red band [42]. As multiple layers of leaves are not entirely visible to the sensor, forests do not necessarily increase their canopy density as they become taller. In addition to this, biomass estimation methods based only on spectral information are complicated by the presence of canopy shadowing from large stands and the heterogeneity of forest stand structures [43-45]. Vegetation indices have shown low to moderate agreements with field data in temperate and boreal forests, where canopy cover is more sparse and there is less species diversity [46,47]. However, in tropical and subtropical regions, with high biomass levels and multi-storied forest canopies, and where there is a greater diversity of tree species, vegetation indices have shown less sensitivity to canopy variations, with low or insignificant results [33].

If changes in direct reflectance, or vegetation indices, are unlikely to show subtle degradation, it is possible that changes in the texture of reflection or index patterns will show after disturbance. The texture of images has shown potential for overcoming the existing problems with biomass saturation [48], both in optical and SAR images [46,4952], and thus it would follow that the same could be true for biomass change. Formally, texture analysis is an image processing technique that measures the variability in pixel intensity among neighboring pixels within a window of fixed size [48]. It contains information on the structural and geometric properties of forest canopies [53]. However, most of the previous texture-based biomass estimation methods have used medium resolution images, such as the $30 \mathrm{~m}$ resolution Landsat TM data [54,55], with fewer studies employing higher resolutions datasets $[46,48]$. Texture metrics derived from finer spatial resolutions is expected to correlate better with field data, as the pixels will not mix several large canopies (which likely have diameters in the 10-30 m range) [50,56-59]. So far, texture-based biomass models have been developed to produce one-time maps of forest biomass $[48,54]$. In order to determine forest gains and losses, two such maps need to be subtracted from each other. The uncertainty on the final product is computed from the propagation of the combined uncertainties of the two static maps, which means that errors at the pixel level can be very large [60]. Considering that forest degradation is a dynamic process, one way to reduce these uncertainties might involve deriving a single regression model on the difference images. This approach requires experimental data of biomass change $(\triangle \mathrm{AGB})$ to derive the model, where the size and timeframe of the disturbance is precisely known.

This study makes use of field data of $\triangle A G B$, collected in forest inventory plots where tree biomass loss has been determined through experimentally controlled logging of different intensities, and links it to the before/after logging differences in band reflectance, NDVI and texture for a variety of commercial and open optical multispectral data, at a range of resolutions $(0.3-30 \mathrm{~m})$. The overall aim of the study, therefore, is to ascertain the best combination of parameters and resolutions for detecting tropical forest degradation, evaluating the performance of both spectral and textural information. Local biomass change maps are then produced to give an indication of the prediction 
quality of the best performing models for potential use in forest research and monitoring applications.

\section{Materials and Methods}

\subsection{Study Area}

The South Eastern Peruvian Amazon, including the Madre de Dios region, has been identified by the Peruvian government as a tropical 'Capital of Biodiversity' The area is threatened by deforestation and degradation following the paving of the tri-national interoceanic highway, opening up the area for development, and prolific illegal goldmining operations [61]. Our study area is located in the North Eastern part of Madre de Dios $\left(11.02{ }^{\circ} \mathrm{S}, 69.72^{\circ} \mathrm{W}\right)$, in the territory of the Indigenous Bélgica Yine Community, which lies on the border between Peru and Brazil, on the right bank of the Acre River. The Bélgica hold property and use rights over an area of 53,394 hectares, divided between agricultural use, timber extraction and forest conservation. In 2010, the Bélgica received certification from the Forest Stewardship Council (FSC) and contracted a logging company, MADERYJA, to carry out certified timber harvesting within their forest concession [62]. The study plots are located at 300 meters above sea level, in an area of planned logging operations. The dense forest canopy reaches heights of up to 40 meters and is very rich in tree species, for a total of 85 species in the surveyed area and an average stem density of about 650 trees ha ${ }^{-1}$. The dominant vegetation type in this area is lowland tropical rainforest, characterised by a high turnover and tree mortality rates of $2.2 \%$ year $^{-1}$ [63]. The climate is warm, humid and seasonal. The dry season occurs from May to October and the rainy season from November to April. Data from the Tropical Rainfall Measuring Mission (TRMM 3B43) shows that the area receives a large amount of rain, with an average of $2915 \mathrm{~mm}_{\text {year }}{ }^{-1}$ for the decade 2009-2019 [64].

\subsection{Field Data}

Forest inventory data from four 1-ha plots was collected during May 2019, and again in October 2020, to measure biomass change resulting from selective logging in July 2019. To enhance the accuracy of the biomass estimates, we used Terrestrial Laser Scanning (TLS), providing digital three-dimensional models of every tree in the plot. We also collected UAV laser scanning (LiDAR) and multispectral optical data $(<10 \mathrm{~cm}$ spatial resolution) by flying two fixed-wing drones over the plots, part of the forest concession and the village area. Unfortunately, international travel bans following the spread of Covid-19 have not yet permitted the collection of post-logging TLS data, and delayed the second part of the UAV LiDAR measurements to September 2021 (data not available at the time of publication).

The 1-ha Permanent Sample Plots were established in the forest concession, along the road that connects Bélgica to Iñapari, following a West-East direction. The plots were located over flat ground, at a distance of maximum $300 \mathrm{~m}$ from the road, to facilitate the TLS operations and ensure accessibility from the UAV. The plots were designed to include loggable tree species that were of interest to the community, especially for their use in building projects, and which were selected by community members during plot reconnaissance. Two of the plots were square, $100 \mathrm{~m} \times 100 \mathrm{~m}$, and two were rectangular plots of $145 \mathrm{~m} \times 70 \mathrm{~m}$, with orientations spanning $0-40^{\circ}$ North. The locations of the plot corners were measured by a differential GPS and corrected using the coordinates of the integrated GNSS receiver of the TLS. We followed standard forest inventory protocols [65] to collect information on Diameter at Breast Height (DBH), species, $X$ and $Y$ coordinates, damage and mortality classes for each stem in the plot with $\mathrm{DBH}$ $>10 \mathrm{~cm}$. Each tree was visually assessed for damage and then categorised according to the percentage of its remaining biomass $(25,50,75$ or $90 \%)$ as compared to an intact

\footnotetext{
1 Law No. 26311 “Declaran Capital de la Biodiversidad del Perú al Departamento de Madre de Dios”.
} 

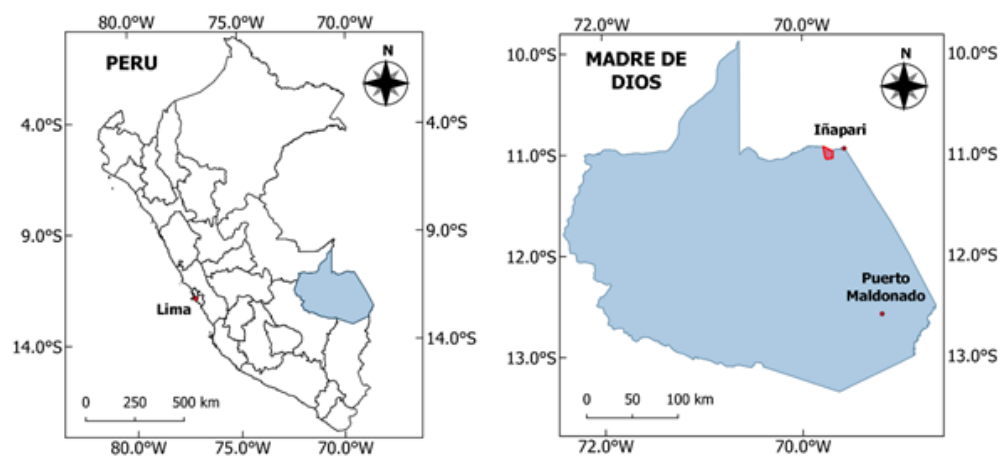

(b)
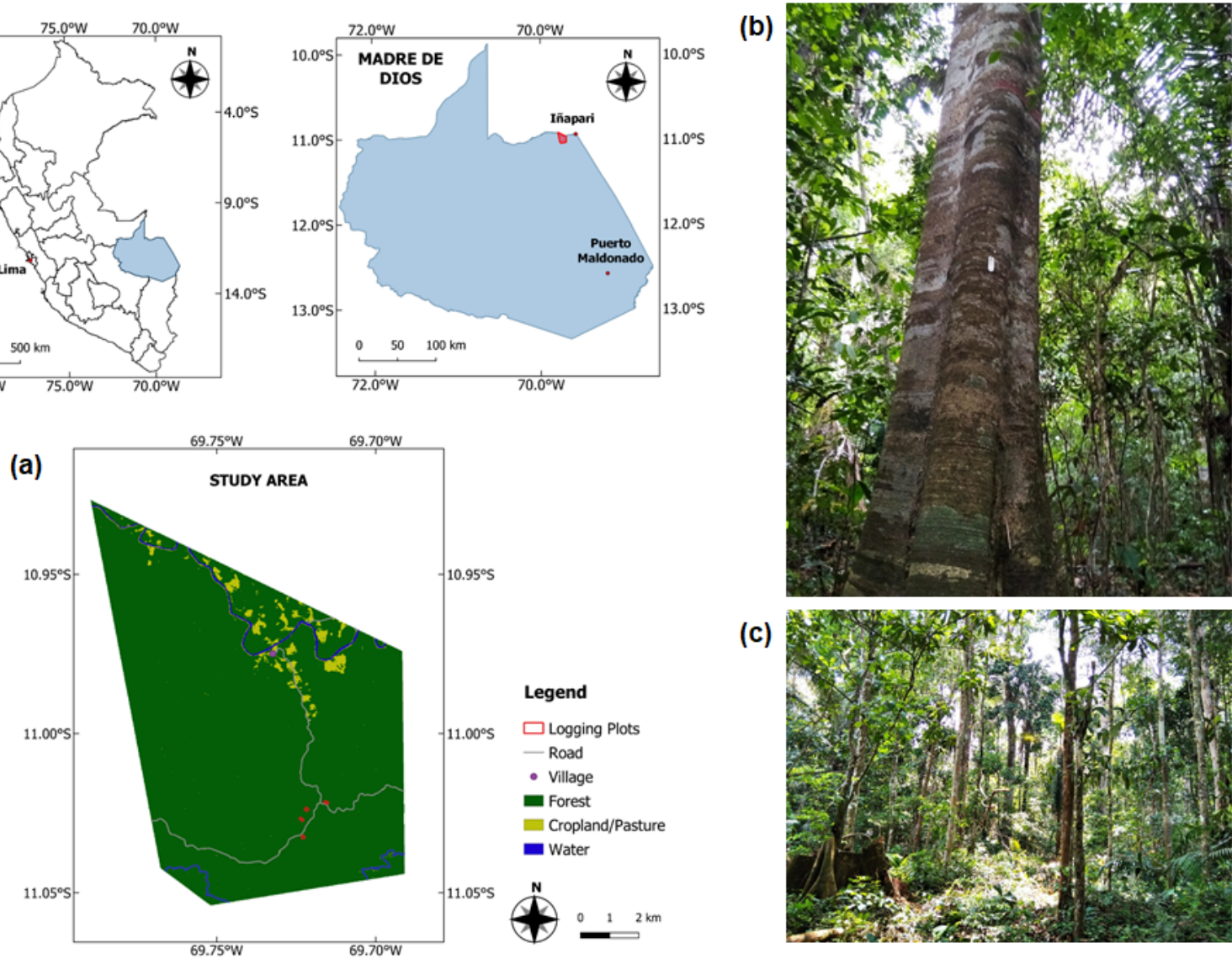

(c)

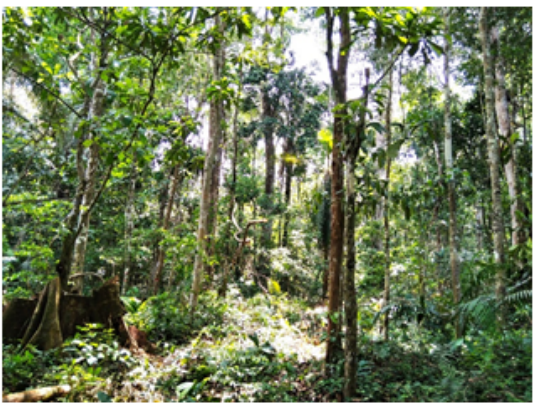

Figure 1. (a) Location and Land Cover Map of the study area, approximately $30 \mathrm{~km}$ west of the town of Iñapari, in the Madre de Dios Region of Peru. The Land Cover Map is a simple supervised classification produced by the authors derived from PlanetScope $3 \mathrm{~m}$ resolution data from July 2019. The images on the right hand side show an example of the forest in the study plot C1: (b) before and (c) after logging took place.

stem. Wood density was derived from species information using a global wood density database [66]. After the pre-logging measurements, Bélgica extracted a total of 24 trees, in different proportions in each plot, to simulate a range of degradation events. For the post-logging forest inventory, the direction of tree felling and the collateral damage caused by the logging operations was also noted.

To convert forest inventory metrics into AGB we used the pantropical allometric model from [67], using field-derived DBH $(D)$ and wood density $(\rho)$, and a regional environmental stress factor $(E)$ with an average value of 0.068 across the four plots. The equation is in the following form:

$$
\mathrm{AGB}=\exp \left[-1.803-0.976(E-\ln (\rho))+2.673 \ln (D)-0.0299 \times[\ln (D)]^{2}\right]
$$

Unfortunately, individual-tree biomass estimates from allometric equations are found to have large uncertainties associated with their values, with an error of about $50 \%$ of the mean [67]. This error is even greater for large trees $(\mathrm{DBH}>70 \mathrm{~cm})$ [68], because of a bias towards small trees in allometric samples and the greater variations in growth forms and biomass for large stems [69]. On the other hand, it was found that AGB estimates from TLS measurements provide a better agreement with the reference data from destructive harvest experiments, with a mean tree-scale relative error of $3 \%$ [70]. Considering that the logged trees in this study have an average DBH of $79 \mathrm{~cm}$, and the 
number of extracted trees varies between 2 and 9 in each plot, we used TLS-derived AGB for the logged stems, yielding likely a more accurate measurement of biomass change.

TLS data were collected using a Riegl VZ-400 scanner, following the protocols outlined in [71]. Each plot was subdivided in squares of $10 \times 10 \mathrm{~m}$ and two scans were obtained at every grid intersection point. The point clouds of the logged trees were extracted using the treeseg package [72]. From the quantitative structural models (QSMs) [73,74], the AGB of each logged tree was derived by multiplying the model volume by wood density. Total AGB loss in each plot was then obtained by summing the TLS-derived AGB of the logged trees plus the change in AGB of the remaining trees as measured from the field surveys (Table S1, Figure 2). Unfortunately, processed TLS data volumes were not available for non-logged trees in the plots, so no comparison between allometric and TLS biomass values could be made for these trees. We expect that the much larger number of non-logged than logged trees in each plot, and their smaller average size, means that this difference is not important. On the other hand, if we use allometric equations for the logged trees, then the biomass removed per plot is overestimated by an amount ranging between $13 \%$ to $29 \%$, as compared to the biomass change values derived from the TLS data (Table S2).



Figure 2. AGB loss in $\mathrm{Mg} \mathrm{ha}^{-1}$ for the four 1-ha selectively logged plots. Forest loss amounts between $5 \%$ and $30 \%$ of initial biomass.

\subsection{Satellite Data Acquisition and Pre-Processing}

Commercial and open remote sensing data were collected over the field site before and after the logging event (Table 1). As part of the FODEX experiment, we tasked and collected Very High Resolution (VHR) and high resolution commercial satellite imagery from WorldView-3, Planet Skysat and SPOT-7. High and medium resolution data from PlanetScope, Sentinel-2 and Landsat 8 was also downloaded for the same period of time. To minimise seasonal effects, we aimed at collecting images that were captured in the same month of the year, and preferably at the same time of the field survey; however, the presence of cloud cover was a limiting factor, especially in the case of commercial acquisitions.

Table 1. Summary of satellite data acquisitions used in this study.

\begin{tabular}{clcccc}
\hline Sensor & Acquisition & Resolution $[\mathrm{m}]$ & Revisit Time & Pre-Logging Date & Post-Logging Date \\
\hline WorldView-3 $^{*}$ & Commercial & 0.3 & $4-5$ days & $10 / 07 / 2019$ & $26 / 05 / 2020$ \\
SkySat & Commercial & 0.8 & $4-5$ days & $15 / 07 / 2019$ & $17 / 06 / 2020$ \\
SPOT-7 & Commercial & 1.5 & $1-3$ days & $10 / 07 / 2019$ & $12 / 06 / 2020$ \\
PlanetScope & Commercial $*$ & 3 & Daily & $10 / 07 / 2019$ & $16 / 07 / 2020$ \\
Sentinel-2 & Open & 10 & 5 days & $09 / 07 / 2019$ & $28 / 07 / 2020$ \\
Landsat 8 & Open & 30 & 16 days & $05 / 07 / 2019$ & $22 / 05 / 2020$ \\
\hline
\end{tabular}

* Only collected on request.

** Non-commercial access through Planet's Education and Research Program [75] or the NICFI Program [38]. 
Launched on 13 August 2014, WorldView-3 is the highest spatial resolution optical satellite available for civilian applications. It is equipped with a panchromatic band (450 - $800 \mathrm{~nm}$ ) at $0.31 \mathrm{~m}$ spatial resolution and can also provide eight multispectral bands in the visible and near-infrared (VNIR, $400-1040 \mathrm{~nm}$ ) at $1.24 \mathrm{~m}$ resolution and 8-band shortwave infrared (SWIR, 1195 - $2365 \mathrm{~nm}$ ) imagery at $3.7 \mathrm{~m}$ resolution. The instrument swath width is of $13.1 \mathrm{~km}$, allowing the acquisition of off-nadir images with an angle of up to 20 degrees, with a revisit time of 4.5 days. Two WorldView- 3 images over the study area were tasked from the satellite data provider Digital Globe and acquired on 10 July 2019 and 26 May 2020. Only the panchromatic and blue, green, red and near-infrared (BGRN) bands were made available for this study. Imagery was delivered in product level LV2A, meaning that the data had been radiometrically corrected and geo-referenced to World Geodetic System (WGS) 1984 datum and the Universal Transverse Mercator (UTM) zone 19S projection. For each band, digital numbers were converted into topof-atmosphere radiance using the absolute radiometric calibration factors and effective bandwidths available in the metadata files. The images were then normalised for solar spectral irradiance by conversion to top-of-atmosphere reflectance. The calibration steps described here were performed according to the formulas and procedures provided by [76] and using the Geospatial Data Abstraction Library (GDAL, http:/ / www.gdal.org/, version number 3.2.2) [77] implemented in Python. To enhance the spatial details of the multispectral data, the panchromatic band was fused with the multispectral bands, using a pansharpening operation and applying a cubic resampling method. The resulting product, at $0.3 \mathrm{~m}$ resolution, was georeferenced using the QGIS software (version 3.10) by manually identifying and matching individual trees from the Canopy Height Model (CHM) of the study area, a LiDAR-derived product with a spatial resolution of $25 \mathrm{~cm}$ and a geometric accuracy of $1.8 \mathrm{~cm}$ [35]. The pre-logging and post-logging georeferenced images were then aligned to match their extents.

The SkySat constellation, operated by Planet Lab, consists of a fleet of 21 commercial high-resolution microsatellites, equipped with optical and near-infrared imaging systems. The first satellite, SkySat-1, was launched on 21 November 2013. The SkySat constellation provide a panchromatic band $(450-900 \mathrm{~nm})$ with a resolution of $0.58-0.86 \mathrm{~m}$ and four multi-spectral bands (blue: 450 - $515 \mathrm{~nm}$; green: 515 - $595 \mathrm{~nm}$; red: 605 - $695 \mathrm{~nm}$; near-infrared: $740-900 \mathrm{~nm}$ ) with a resolution of $0.72-1.0 \mathrm{~m}$. The system has a swath width of $\sim 6.5 \mathrm{~km}$ at nadir and revisits times of $4-5$ days per satellite [78]. Two SkySat imagery over the study area were tasked from Planet Labs and acquired on 15 July 2019 and 17 June 2020. The images were downloaded from the Planet Explorer platform [79] and acquired as an already orthorectified, pansharpened 4-band BGRN product at 0.81 $\mathrm{m}$ spatial resolution. To convert the digital numbers into top-of-atmosphere reflectance, each pixel value was multiplied by a radiometric scale factor and then corrected for solar spectral irradiance, as detailed in the technical sheet provided by Planet Labs [78]. The calibrated products were then georeferenced using the processed WorldView-3 images. As for the WorldView-3 data, the pre-logging and post-logging images were aligned to match their extents.

The SPOT ("Satellite pour l'Observation de la Terre") series was developed within the French National Space Program and has been providing high-resolution, wide-area multispectral imagery since 1986. SPOT-7 was launched on 30 June 2014 and consists of four multispectral bands: blue $(450-520 \mathrm{~nm})$, green $(530-590 \mathrm{~nm})$, red $(625-695$ $\mathrm{nm})$, and NIR $(760-890 \mathrm{~nm})$ at a spatial resolution of $6 \mathrm{~m}$, and one panchromatic band $(450-745 \mathrm{~nm})$ at a spatial resolution of $1.5 \mathrm{~m}$. SPOT-7 has revisits of 1 to 3 days and its imaging swath is $60 \mathrm{~km}$ at nadir. Two archived SPOT-7 imagery, captured on 10 July 2019 and 12 June 2020, were downloaded from the Airbus GeoStore Web Portal (http://www.intelligence-airbusds.com). Access to the imagery was possible through ESA's Third Party Mission scheme. The images were obtained in product level Ortho and in units of surface reflectance, which means that the data had been orthorectified and radiometrically corrected from sensor calibration and systematic 
atmospheric effects. The product was already pan-sharpened and it was delivered as a 4-band BGRN multispectral image at a spatial resolution of $1.5 \mathrm{~m}$.

First launched in 2016, the PlanetScope CubeSat constellation is operated by Planet Labs, with more than 180 individual nano-satellites named "Doves", which capture the entire Earth's surface at $3 \mathrm{~m}$ spatial resolution on a daily basis. PlanetScope imagery contains four spectral bands, i.e. blue (455 - $515 \mathrm{~nm})$, green $(500-590 \mathrm{~nm})$, red (590 $670 \mathrm{~nm})$, and NIR $(780-860 \mathrm{~nm})$. Planet offers free monthly limited PlanetScope images to the scientific research community through the Education and Research Program [75]. Two images were acquired on 10 July 2019 and 16 July 2020 as an orthorectified, Level-3B analytic surface reflectance product, which has incorporated geometric and radiometric corrections, and is atmospherically corrected by Planet Labs using the $6 \mathrm{~S}$ radiative transfer model with ancillary data from MODIS [78,80].

The European Space Agency (ESA) Sentinel-2 mission supplies wide-swath (290 $\mathrm{km}$ ), high-resolution, multi-spectral data, supporting land monitoring research; the imagery complements and enhances other missions, such as Landsat and SPOT. The Sentinel-2 constellation is made of two polar orbiting satellites, Sentinel-2A and Sentinel2B, launched on 23 June 2015 and 7 March 2017, respectively. Each satellite carries onboard an optical imaging sensor MSI (Multi-Spectral Instrument) with the capabilities of recording reflected radiance in 13 spectral bands: four VNIR bands at $10 \mathrm{~m}$ spatial resolution, six red edge and SWIR bands at $20 \mathrm{~m}$ spatial resolution, and three atmospheric correction bands at $60 \mathrm{~m}$ spatial resolution. Each satellite has a revisit frequency of 10 days, while the combined constellation has a repetition cycle of 5 days. As a consequence, Sentinel-2 provides dense time series imagery, with data open to all. For this study, two-cloud free Sentinel-2 MSI granules acquired on 9 July 2019 and 28 July 2020 were downloaded from the Copernicus Data Hub [81] as Level-2A surface reflectance product. We used the bands available at $10 \mathrm{~m}$, ie. blue (B2: $490 \mathrm{~nm})$, green (B3: $560 \mathrm{~nm})$, red (B4: $665 \mathrm{~nm}$ ) and NIR (B8: $842 \mathrm{~nm}$ ). Sentinel-2 Level 2A products provided by ESA are generated by the Sen2Cor processor [82], already orthorectified as $100 \times 100 \mathrm{~km}$ ortho-images in UTM/WGS84 projection and corrected for atmospheric effects.

The Landsat 8 satellite is part of the long-running Landsat joint mission of the United States Geological Survey (USGS) and NASA. It was launched on 11 February 2013 with the operational land imager (OLI) and the thermal infrared sensor (TIRS) onboard. The OLI collects measurements for nine spectral bands in the VNIR and SWIR at $30 \mathrm{~m}$ spatial resolution, including an infrared band for cirrus detection and a deep blue band for coastal monitoring. It also provides a single, panchromatic band at $15 \mathrm{~m}$ spatial resolution. The TIRS measures land surface temperature in two thermal infrared bands at $100 \mathrm{~m}$ spatial resolution. The system images the entire Earth's surface with a repeat cycle of 16 days and over a $185 \mathrm{~km}$ swath. Two Landsat 8 tiles from 5 June 2019 and 22 May 2020 were freely downloaded from the USGS Earth Explorer web ( https: / /glovis.usgs.gov/) as a standard Level-2 surface reflectance product with the UTM/WGS84 projection. The data delivered by USGS is corrected for atmospheric effect using the Land Surface Reflectance Code (LaSRC) [83]. Only the BGRN bands are used in this study, i.e. blue (B2: $485 \mathrm{~nm})$, green (B3: $563 \mathrm{~nm})$, red (B4: $655 \mathrm{~nm}$ ) and NIR (B5: $865 \mathrm{~nm})$. Given the availability of the $10 \mathrm{~m}$ resolution Sentinel-2 imagery, the Landsat BGRN bands were not pansharpened using the panchromatic data.

When performing multi-temporal analysis, image normalization is critical for ensuring homogeneity between two or more scenes captured under different atmospheric conditions or illumination geometries. This is achieved by altering the radiometric properties of the image series using the histogram of a reference image [84]. In this study, normalization is performed using the histogram matching function from the Python scikit-image package [85]. For each sensor, the pre-logging image was chosen as the reference image and the histogram of this reference image was matched to the post-logging image. The same histogram matching technique was also used to correct for the presence of cloud shadow over plot C2 in the post-logging WorldView-3 image. 
In this case, the pixel values of the shadow-covered region are recovered by matching the histogram of the shadow region to the histogram of the non-shadow area of the same land surface class [86].

The image pre-processing pipeline is shown in Figure 3. In addition to the steps described in the diagram, PlanetScope, Sentinel-2 and Landsat 8 were resampled to a $1 \mathrm{~m}$ resolution using a Nearest Neighbour convolution, to allow for easy and direct comparison with the higher resolution data.

1. Satellite Image Pre-Processing
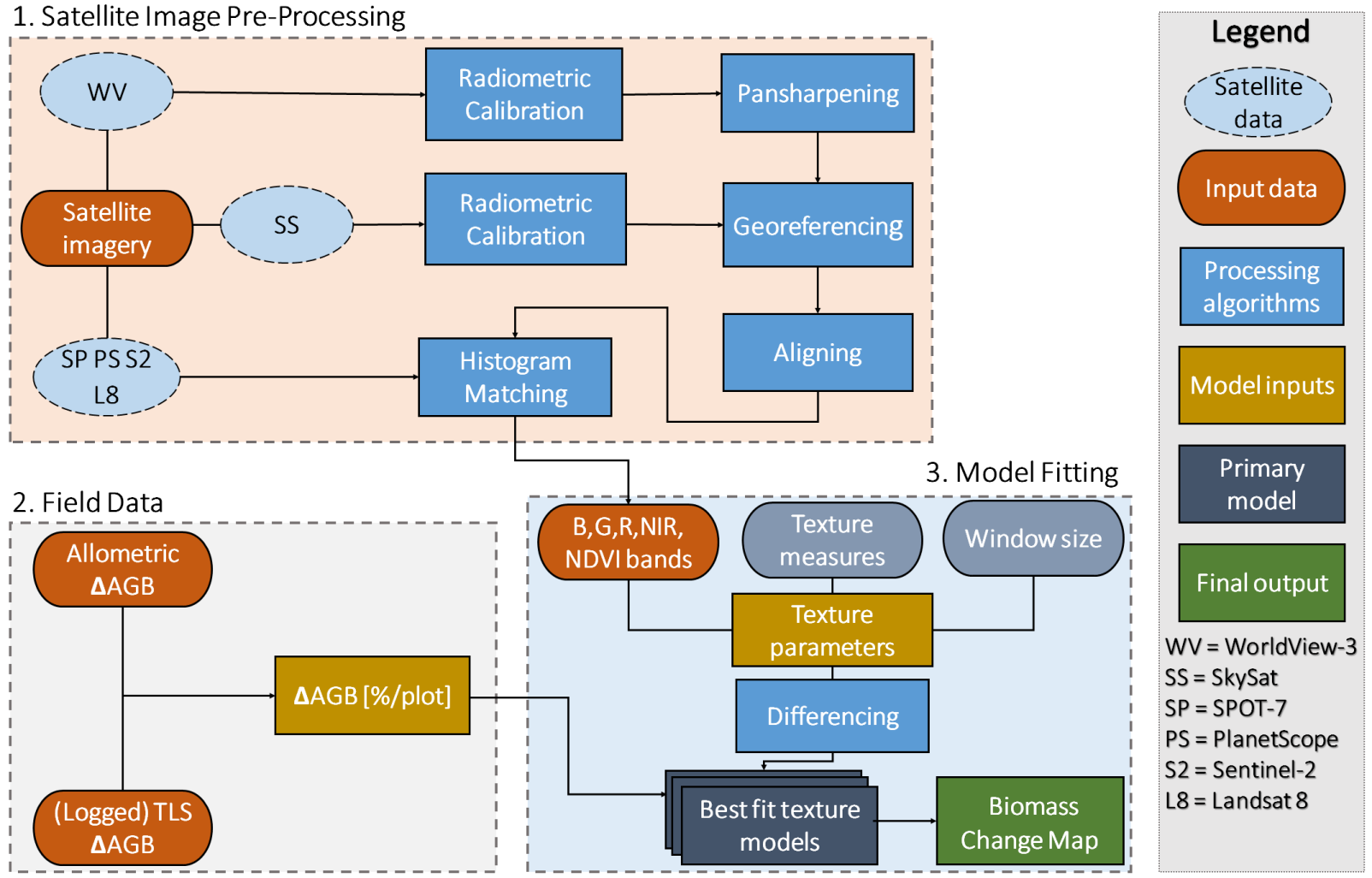

Figure 3. General methodology workflow used for producing biomass change estimates over the study area using fieldderived $\triangle \mathrm{AGB}$ and remotely sensed data.

\subsection{Simple Reflectance, NDVI and Texture Measures}

After preprocessing, the resulting red and NIR bands were used for the calculation of the Normalized Difference Vegetation Index (NDVI):

$$
\mathrm{NDVI}=\frac{\mathrm{NIR}-\text { Red }}{\mathrm{NIR}+\text { Red }}
$$

The choice of this particular index was motivated by its widespread use in landcover change detection and monitoring of vegetation dynamics $[87,88]$, and the fact that it can be calculated from all the six satellite dataset types without the need of sensor-specific calibration constants, making it suitable for multi-sensor comparison. All the sensors had blue, green, red and NIR bands (BGRN), so these were also tested individually, and stacked into a raster with the NDVI band for subsequent analysis.

Identifying appropriate textures involves the selection of suitable texture measures, moving window sizes, and spectral bands from which to calculate it. In terms of texture measures, we based our selection on previous research predicting biomass values from optical satellite data $[45,46,48,55]$. Among the different techniques, local standard deviation was chosen as a promising method for detecting canopy loss. Figure 4 shows the Sentinel-2 NDVI time series of the degraded plot $\mathrm{C} 1$ as compared to the same signal 
from an intact area. This background plot was computed as the average of five 1-ha plots located in the study area which did not experience any logging activity, and therefore are used as a data point with zero biomass change. A time series of the degraded plot derived from the NDVI mean (Figure 4a) does not show any significant variation immediately before and after logging, compared to the background signal. On the other hand, when using a textural metric, the standard deviation of the NDVI computed in a $3 \times 3$ pixel moving window, a signal peak is observed in correspondence of the logging event, that is not seen in the background signal (Figure $4 \mathbf{b}$ ).

(a)

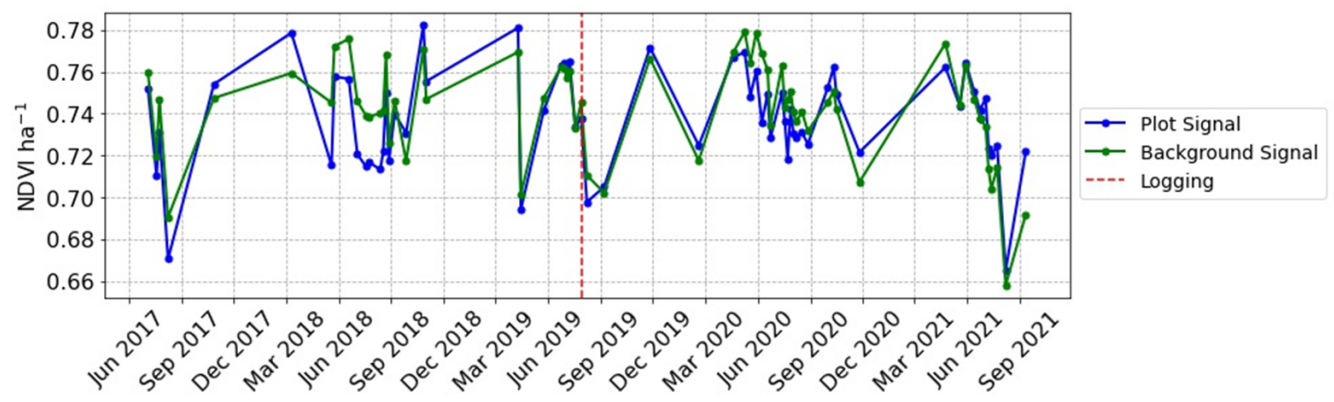

(b)



Figure 4. Sentinel-2 NDVI time series for the degraded plot C1 and background signal before and after the logging event, indicated by the dashed red line. (a) NDVI mean and (b) NDVI texture for a $3 \times 3$ pixel moving window. The time series derived from texture shows a seasonal trend, with a peak in the dry season. An increase in standard deviation is observed in correspondence of the logging event.

Texture is a function of local variance and is directly related to the resolution and size of the dominant feature. In this study, this corresponds to the size and spacing of the tree crowns. Low variance is expected in high resolution images where the pixel size is smaller than the tree crown size, though it will rise around the edge of such crowns, effectively acting as an edge detector. As pixel size increases to a scale that is comparable to the tree crown, local variance increases too, and this should especially apply to tropical forests, rich in tree species and with heterogeneous canopy structures [46]. A small moving window amplifies the difference within the window frame, increasing image noise, but it retains a high spatial resolution. On the other hand, a large window may not extract the necessary information due to an excessive smoothing of the textural variations [55]. Considering the large spread of resolutions in our dataset (0.3 - 30 $\mathrm{m})$, we tested nine different sizes of moving windows $(3 \times 3,5 \times 5,7 \times 7,9 \times 9,11 \times 11$, $15 \times 15,19 \times 19,25 \times 25,45 \times 45)$ using a texture metrics of standard deviation to check for variations within neighbouring pixels.

In summary, the following remotely sensed measures were used for this analysis, for each optical sensor:

- $\quad$ Spectral reflectances of each individual band (blue, red, green, NIR);

- Texture parameters of each individual band (blue, red, green, NIR) for 9 window sizes;

- $\quad$ NDVI (mean and texture for 9 window sizes). 
To link the field biomass change with the satellite measurements, we extract the pre-logging and post-logging metric value for each remote sensing variable for all the pixels within the field plots. The difference pre- and post- logging was then calculated for each pixel, and then the mean difference calculated over the whole plot. For the texture parameters, the difference was squared first, and then the mean squared texture value of each plot was calculated. This ensures that the positive and negative values resulting from the differences between pre-logging and post-logging textures do not cancel out when taking the plot average, with the consequent loss of useful information. This squaring can be thought of as moving the difference from standard deviation to variance space.

\subsection{Statistical Analysis}

The relationship between field-measured biomass change and the difference of the remotely sensed variables per plot was analysed using linear regression, with the strength of the relationships assessed using Pearson's Correlation (r). $\triangle$ AGB (in units of $\% \mathrm{ha}^{-1}$ ) was used as a dependent variable and the computed remote sensing parameters were used as independent variables. The coefficient of determination $\left(R^{2}\right)$, the $p$-value and the Root Mean Square Error (RMSE) were used to evaluate the regression model performance.

\section{Results}

A visual, multi-scale representation of some of the remotely sensed variables used in this analysis is illustrated in Figure 5, with the RGB images showing plot C1 before and after logging (Figure 5a). Figure $5 \mathbf{b}$ and Figure $5 \mathbf{c}$ show the difference in NDVI and in the texture of the NIR band before and after logging for the same plot.

(a)

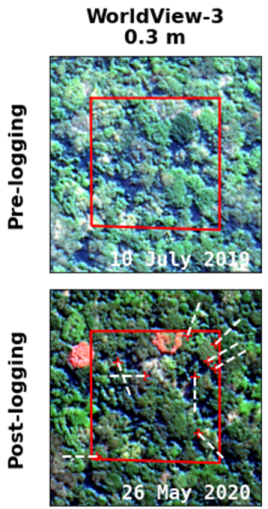

(b)

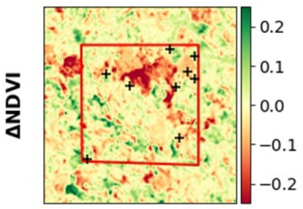

(c)

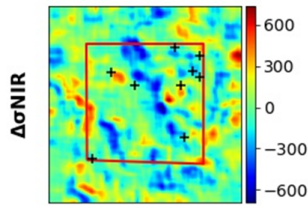

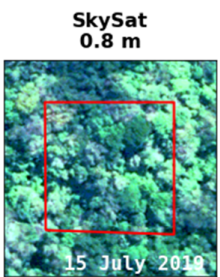
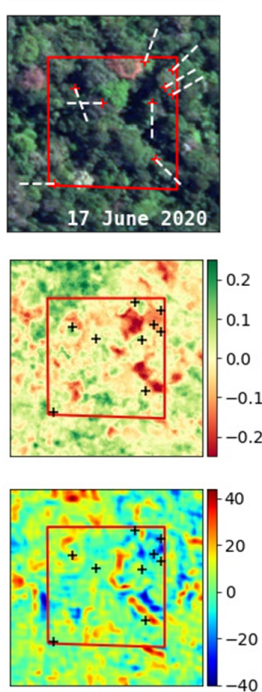
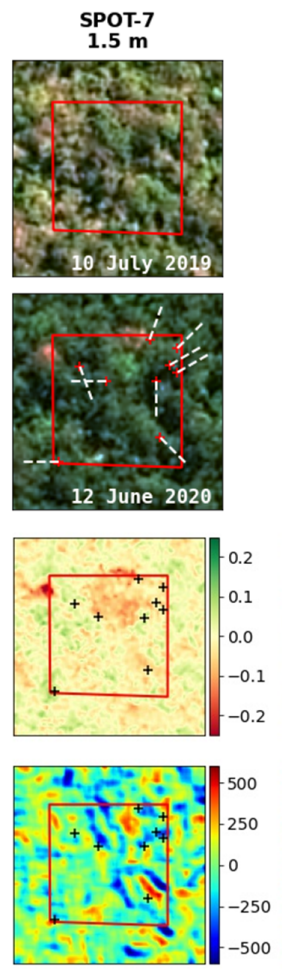
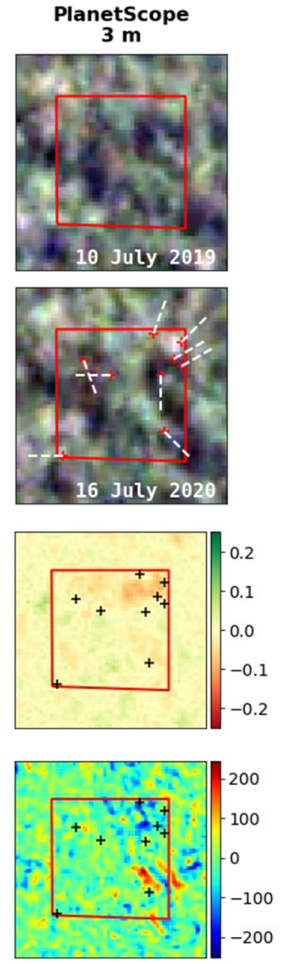
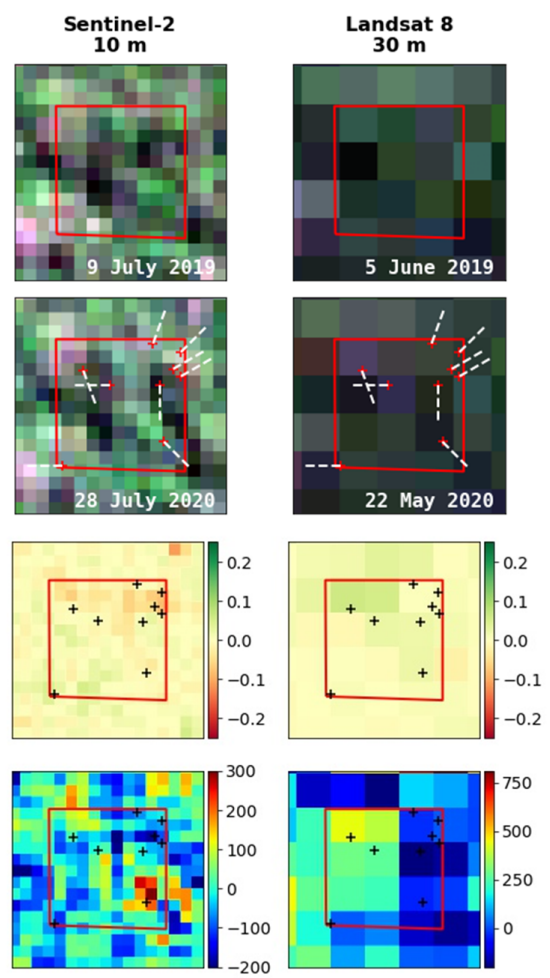

Figure 5. (a) Visual comparison of RGB imagery before and after logging at increasingly coarser resolutions for the plot C1. The post-logging images show the position of the harvested trees as red crosses and the direction of the felling as white dashed lines. (b) Difference in NDVI ( $\triangle$ NDVI) and (c) in NIR texture $(\Delta \sigma \mathrm{NIR})$ for the same plot. The window sizes used for each sensor correspond to those resulting from the best fit models (Table S4). 


\subsection{Relationships between Spectral Reflectances/NDVI and Biomass Change}

Linear regression models were calculated using biomass change as the dependent variable and all other parameters as the independent variables. For the spectral parameters, the best fitting models are shown in Figure 6, with difference in simple NIR reflectance illustrated in Figure $6 \mathbf{a}$ and difference in NDVI shown in Figure $6 \mathbf{b}$. All models show poor performance, with the exception of SkySat $\Delta$ NDVI, with $R^{2}=0.72$ and RMSE of $5.52 \triangle \mathrm{AGB}$ (in units of $\% \mathrm{ha}^{-1}$ ). A full list of the models and corresponding statistics for the difference in spectral reflectance and biomass change, as well as $\Delta$ NDVI and biomass change, is available in Table S3.

(a)
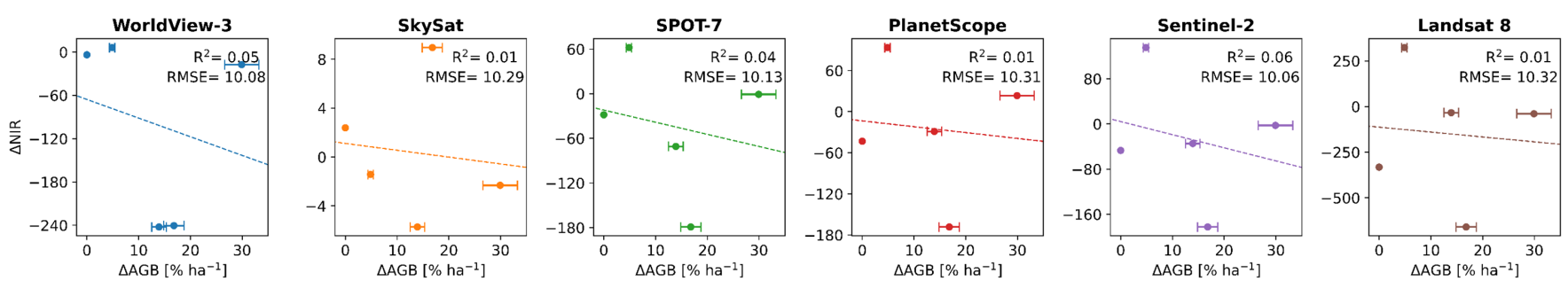

(b)
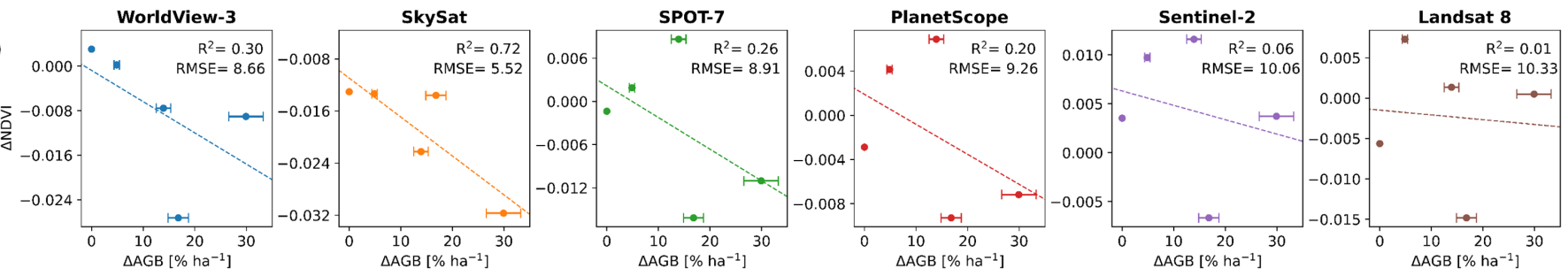

Figure 6. Multi-sensor comparison of regression models for (a) biomass loss and $\Delta$ NIR and (b) biomass loss and $\Delta$ NDVI.

\subsection{Relationships between Texture and Biomass Change}

Table $\mathbf{S} 4$ provides the complete list of all the generated models relating biomass change to the difference in textural parameters. The best-fitting model among all sensors is observed for PlanetScope, obtained from the texture parameter of the NIR band and for a window size of $3 \times 3$ pixels $\left(R^{2}=0.97\right)$. The lowest performance for texture measurement is observed in SkySat, with the best performing model obtained by the texture of the NDVI and using a window size of $7 \times 7$ pixels $\left(R^{2}=0.50\right)$. To illustrate how spectral and textural-based models compare, Figure 7 shows the best-fitting models for texture differences obtained from the NIR band (Figure 7a) and NDVI (Figure 7b).

\subsection{Model Performance}

A notable improvement in the ability to map degradation when using texture over direct changes in spectral data or NDVI is observed for all optical sensors except SkySat (Figure 7a, Figure 6a and Figure 6b), in particular when using texture obtained from the NIR band. This pattern of improvement is illustrated in Figure 8, which compares the RMSE of three models to evaluate their performance for biomass change estimation. The best performing model is obtained from texture of PlanetScope imagery, with RMSE $=1.80 \% \mathrm{ha}^{-1}$. It is followed by SPOT-7 and Sentinel-2, which have one step higher and lower resolution respectively, both showing a significant improvement in model performance when textural NIR is used $\left(\mathrm{RMSE}=5.25 \% \mathrm{ha}^{-1}\right.$ and RMSE $=5.55 \% \mathrm{ha}^{-1}$, respectively). Biomass loss estimation with WorldView-3 is also improved when using the textural parameter $\left(\mathrm{RMSE}=6.35 \% \mathrm{ha}^{-1}\right.$, as compared to $\mathrm{RMSE}=8.66 \% \mathrm{ha}^{-1}$ of a model based on $\triangle$ NDVI). A small improvement is also observed in Landsat 8 , but the error is still too large for justifying the use of Landsat data for small-scale degradation detection. On the other hand, SkySat appears to be the only sensor that performs better when using simple NDVI difference $\left(\right.$ RMSE $=5.53 \% \mathrm{ha}^{-1}$, as compared to RMSE $=7.30$ $\% \mathrm{ha}^{-1}$ for texture-derived NDVI). Given the small sample size and the number of tested 

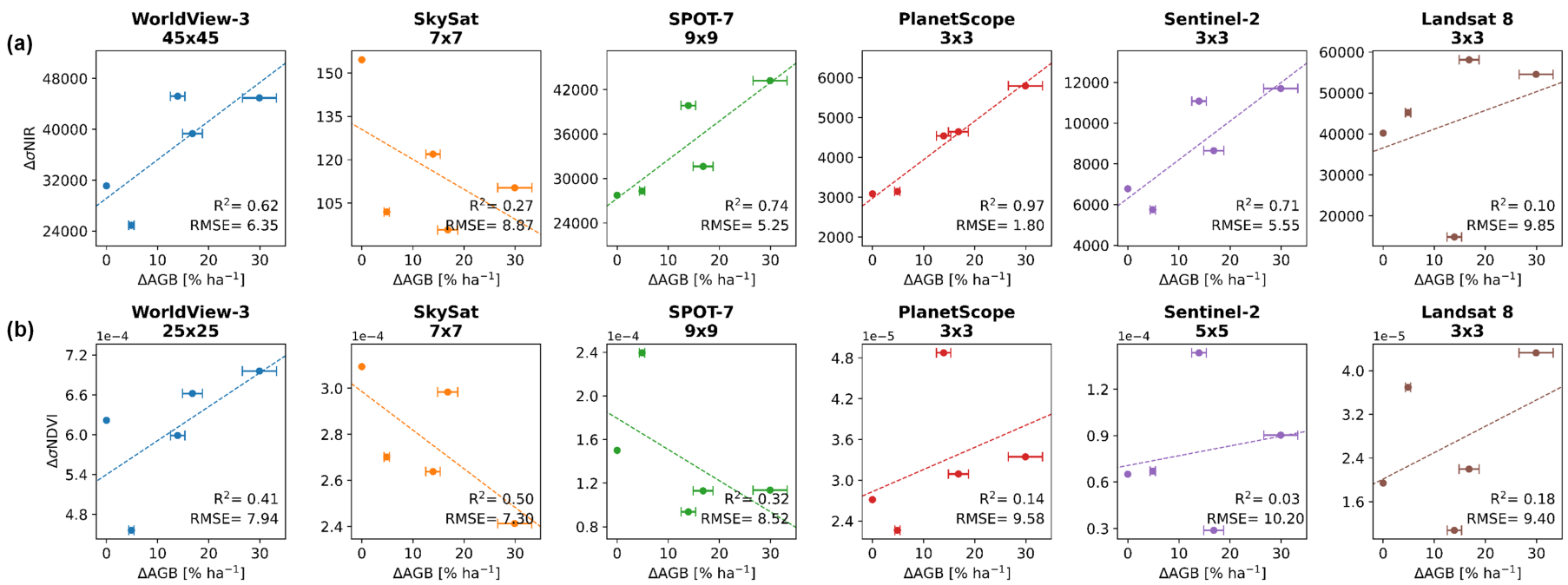

Figure 7. Multi-sensor comparison of the highest performing regression models for predicting biomass loss obtained from the difference in texture of (a) NIR and of (b) NDVI. The window sizes used in generating the models are reported above each subplot.

correlations, the strong relationship between SkySat $\triangle \mathrm{NDVI}$ and biomass change could be coincidential; however, as far as the NIR-derived texture results are concerned, the pattern observed among neighbouring satellites is in favour of the research hypothesis (Figure 8).

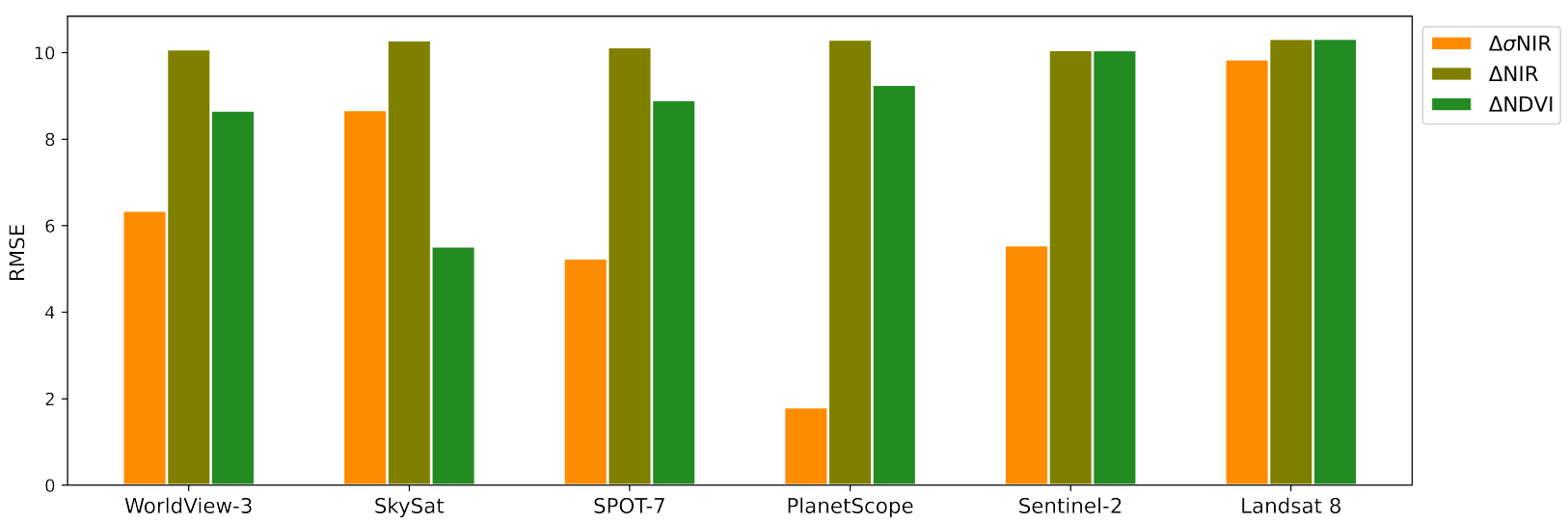

Figure 8. Evaluation of model performance for biomass loss estimation. The graph compares the RMSE of three models estimating biomass loss from the difference in simple NIR $(\triangle \mathrm{NIR})$, difference in NDVI $(\triangle \mathrm{NDVI})$ and difference in texture obtained from the NIR band ( $\Delta \sigma \mathrm{NIR})$.

\subsection{Biomass Change Maps}

Biomass change maps were produced from PlanetScope, SPOT-7 and Sentinel2 texture change data, as those were the optical sensors yielding the highest model performance (Figure 8). Figure 9 compares the three biomass change maps of the study area constructed from the best fitting models, where the textural parameter was calculated from the NIR band on a window of $9 \times 9$ pixels for SPOT-7 (Fig. 9 a), and $3 \times 3$ pixels for PlanetScope (Figure 9b) and Sentinel-2 (Figure 9c) and with a 1-ha resolution. Figure 9 indicates that the PlanetScope biomass change map has the least background noise. Areas of higher degradation, observed in proximity of the village and the river, are in agreement with the observations from the RGB imagery from 2019 and 2020 and correspond to areas of agricultural expansion into the forest concession (Figure 10). 

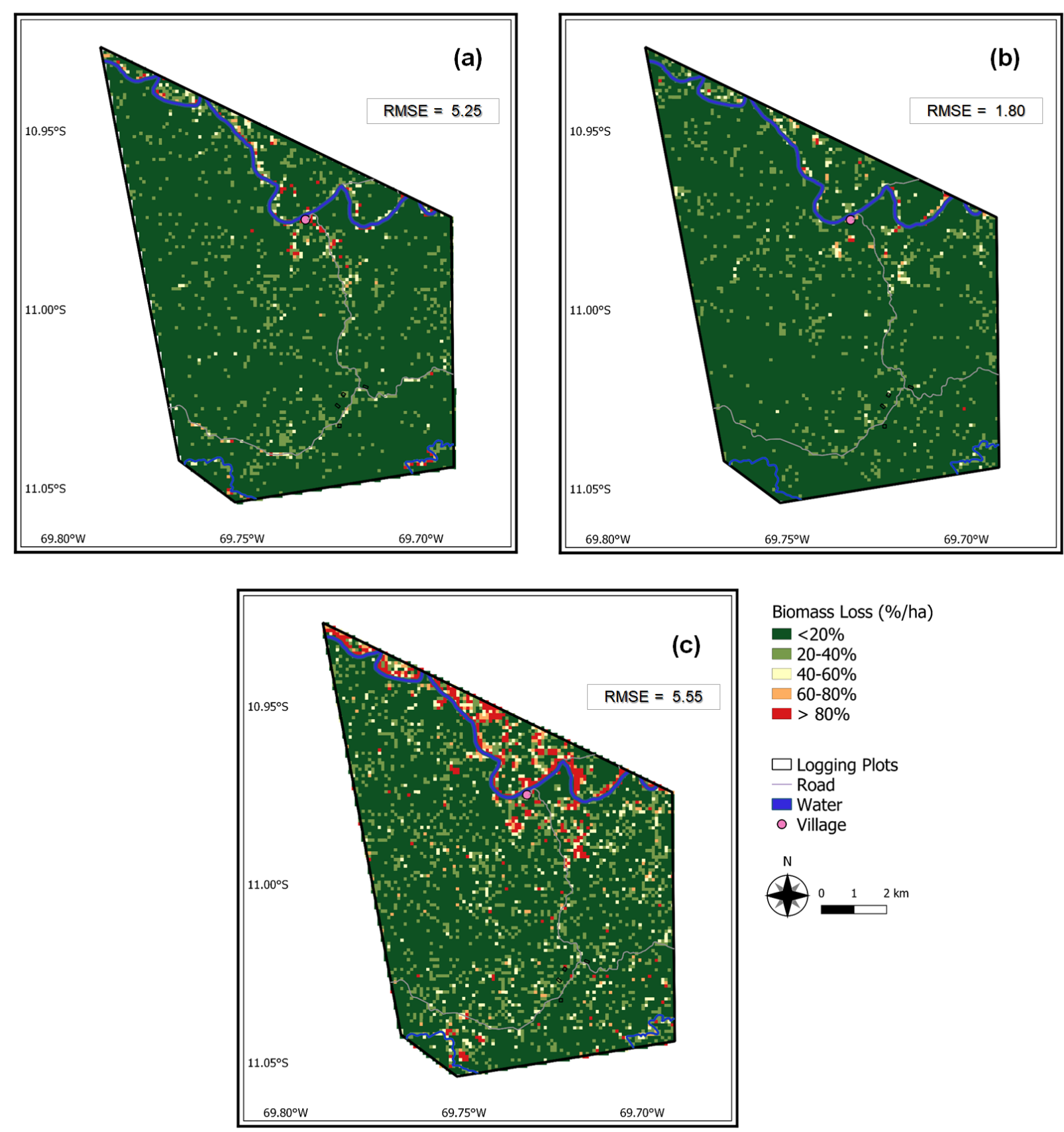

Biomass Loss (\%/ha)

$<20 \%$

$20-40 \%$

$40-60 \%$

$60-80 \%$

$>80 \%$

$\square$ Logging Plots

- Road

Water

o Village

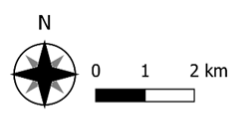

Figure 9. Maps of biomass change (2019-2020) over the study region derived from the texture of the NIR band for (a) SPOT-7,

(b) PlanetScope and (c) Sentinel-2 data for a 1-ha resolution.

\section{Discussion}

In this study we tested the ability of different high-medium resolution optical satellite datasets to detect experimentally-controlled degradation in a tropical forest in Peru. We found that sensors in the $1.5-10 \mathrm{~m}$ range showed a strong ability to detect forest degradation, particularly when analysed using a novel texture-change metric we developed using a window size approximating $10 \times 10 \mathrm{~m}$. The best overall method was found for the $3 \mathrm{~m}$ resolution PlanetScope imagery using a texture parameter obtained from the NIR band and a window size of $3 \times 3$ pixels. Texture-based models developed from the NIR band of SPOT-7 and Sentinel-2 data also showed good performance (Figure 8). A slightly weaker relationship was observed for WorldView-3, with the best 
(a)

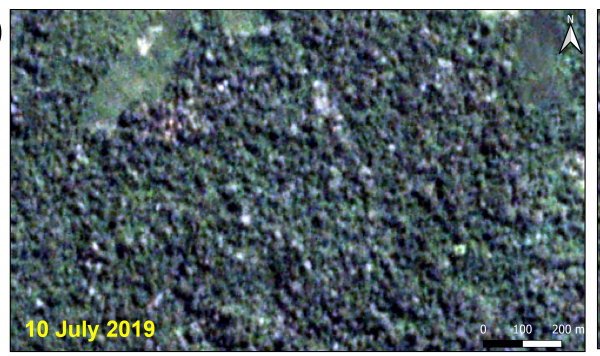

(b)

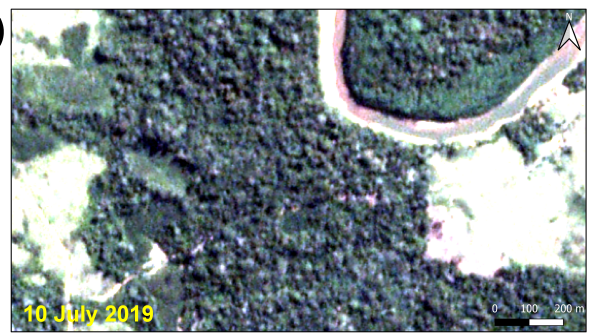



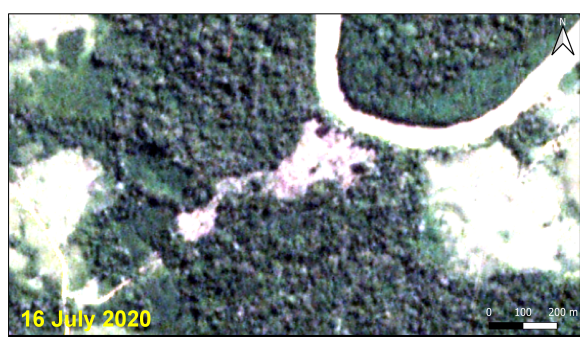

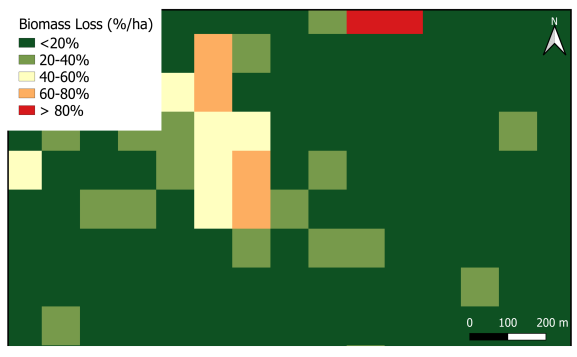

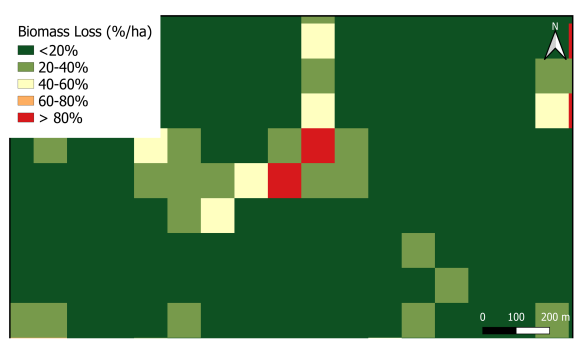

Figure 10. PlanetScope RGB data from 2019 and 2020, showing degradation of two sites, (a) and (b), both undergoing conversion for pasture and agricultural use. The right hand figures show the same location in the PlanetScope biomass loss map from Figure $9 \mathbf{b}$. Visible areas of degradation and deforestation correspond to the high degradation pixels ( $>40 \%$ loss per hectare) in the biomass loss map.

model performance achieved when using a texture measure derived from the NIR band and a $45 \times 45$ pixel window. Overall, this approach shows great potential to transform mapping of forest degradation, though how well it transfers to other areas or types and magnitudes of forest disturbance remains to be seen.

\subsection{Biomass Change Predictions from Texture Analysis}

Previous research has concluded that texture analysis improves AGB estimation performance, compared to the use of spectral parameters or vegetation indices [46,48, 55]. This study confirms that texture parameters correlate more strongly with AGB change, for five out of six sensors analysed. SkySat was the only sensor where the strongest correlation was observed for the difference in NDVI values, though it should be noted that its performance was quite poor compared to other sensors even using NDVI difference. In general, vegetation indices can improve AGB estimates, as the use of band ratios partially reduce the effects of atmospheric conditions and shadows, especially in regions of heterogeneous forest [55]. However, vegetation indices often saturate in high biomass and multi-storied forest canopies [42,43]. While NDVI is computed at the pixel scale, texture is calculated from a neighbourhood of pixels that can be adjusted in size to optimise the potential of texture to measure local variability. Therefore, texture can be an effective measure to detect variations in canopy edges caused by forest fragmentation, especially in the case of close canopy forests. One important step is to identify suitable texture metrics, which requires prior knowledge on the combination of moving window sizes, image bands and texture measures that strongly correlate with changes in forest biomass. In this study, a measure of variance, derived from squaring and then differencing per-pixel standard deviation, was chosen as the texture measure to compute the variability in reflectance among neighbouring pixels, to identify potential areas of abrupt change. We found that the best performing texture-based models were derived from the NIR band (Figure 7a). This is due to the higher penetration depth of this band compared to visible light [42]. As for the moving window size, this depends on the spatial resolution and extent of the observed object. A window that is too small may detect changes in pixel values that are irrelevant for forest change, whereas a window that is too large may make the relevant textural variation invisible [55]. For purposes of detecting forest degradation, the optimal window size 
was selected as the window size that produced the best fitting model. It is important to note that the number of pixels in each window depend on the resolution of the dataset. For PlanetScope, the best result was obtained using a $3 \times 3$ pixel window, corresponding to a physical square window of $9 \times 9 \mathrm{~m}$. For SPOT-7, we found that the best window $(9 \times 9$ pixels $)$ corresponded to a square of $13.5 \times 13.5 \mathrm{~m}$ in size. A very similar result was found for WorldView-3, where a $45 \times 45$ pixel window corresponds to a window size of $14 \times 14 \mathrm{~m}$. In the case of Sentinel-2, the $10 \mathrm{~m}$ pixel resolution puts a lower limit on the minimum size of the moving window. Nevertheless, it is the minimum value $(3 \times 3$ pixels, corresponding to a square of $30 \times 30 \mathrm{~m}$ ) that achieves the highest agreement with the biomass data. These findings indicate that there is an optimum window size for detecting small-scale biomass variations. It is worth noting that for PlanetScope the best value is obtained by the smallest window available. However, if we increase the window to the next available size $(5 \times 5$ pixels, corresponding to $15 \times 15 \mathrm{~m})$, the correlation is slightly weaker $(R=3.44)$, and it gradually worsens as we select larger window sizes. In general, the correlation between biomass change and the remote sensing observation weakens when the size of the window increases or decreases away from this optimum value, and this is true for all the sensors analysed here (Figure S1). This suggests that the measurement of local variance in forest structures is enabled when crown sizes are similar to the window resolution [46].

\subsection{Biomass Change Map Products}

In recent years, high resolution satellite optical data has become more abundant and available, freeing the possibility for forest monitoring to become a more democratic tool, accessed by a wider public. However, uncertainties in the remotely sensed data, especially in image preprocessing and at different levels of the processing chain, AGB calculations based on allometric models, the discrepancy between satellite acquisition date and field inventory date, can affect the accuracy of the remote sensing observations and hence the transferability of the model [55]. As a result, individual satellite-based biomass maps over tropical areas normally have large pixel-level uncertainties [60,89]. Differencing such maps to produce a biomass change product means that substantial spatial errors would be indistinguishable from the physical changes in forest cover. This is the reason why differencing such maps is not recommendable, and there are currently no trusted biomass change maps over the tropics.

In this study we used field measurements of biomass change where the entity and the timescale of the disturbance events is well known, in order to reduce the uncertainty caused by the temporal mismatch between satellite and field data collection. We used change data to directly calibrate our model, deriving a map of biomass change without the need of differencing two static maps. As a result, the biomass change maps developed here are capable of producing direct estimates of forest loss, overcoming the inherent noise caused by error propagation (Figure 9). A visual comparison of the RGB imagery from the two study years 2019 and 2020 has identified areas of forest loss near the village, due to agricultural expansion (Figure 10). These areas correspond to the pixels in the PlanetScope map showing the highest amount of forest loss $\left(>40 \% \mathrm{ha}^{-1}\right)$. Among the three maps constructed from the best performing sensors, PlanetScope yields the highest predictive power, albeit it is not sensitive enough for detecting losses at the lower end of the degradation scale $\left(<20 \% \mathrm{ha}^{-1}\right)$ (Figure $\left.9 \mathbf{b}\right)$. On the other hand, the model performs well at predicting higher levels of biomass change (red pixels in Figure 10), showing that the metrics continues to rise rather than reaching a saturation point at $\triangle \mathrm{AGB}=100 \% \mathrm{ha}^{-1}$. Unfortunately, the difficulty in collecting sufficient ground reference data, spanning a wider range of degradation values (currently limited to 5 $30 \% \mathrm{ha}^{-1}$ ), restricts the sample size used in this study and increases model uncertainty. Furthermore, while validation is an important part of AGB estimation analyses, the lack of further ground reference data makes independent validation impossible at this stage of the research. The acquisition and successive integration of the post-logging 
LiDAR data will improve the prediction and accuracy of our models. We hope that the information presented here on the best combination of optical satellite and textural parameter can be used as a template for future work on biomass change estimation.

\section{Conclusions}

The objective of this study was to link experimental data of biomass change to optical remote sensing observations from six different sensors, spanning resolutions in the range of $0.3-30 \mathrm{~m}$. Models based on spectral and textural information were developed from all the six datasets in order to find the best combination of sensor and remote sensing variable for predicting biomass change in dense tropical forests. Contrary to previous studies, biomass change was not estimated by subtracting two static AGB maps. Field inventory data collected before and after selective logging allowed for building models where biomass change was directly related to the change in the remote sensing variable. From this analysis we draw the following conclusions:

- $\quad$ Biomass change models built on image texture are more strongly correlated to $\triangle \mathrm{AGB}$ than those built on pure spectral signatures. This is true for five out of the six sensors analysed here. SkySat was the only case where the strongest correlation with $\triangle \mathrm{AGB}$ was observed when using a vegetation index;

- A comparative study showed that the best performing model was obtained for PlanetScope data, achieving a $\mathrm{R}^{2}$ of 0.97 and RMSE of $1.80 \Delta \mathrm{AGB} \% \mathrm{ha}^{-1}$. This model consists of a texture obtained from the NIR band in a $3 \times 3$ pixel window. In general, high correlations were observed for four out of six sensors when using the texture of the NIR band;

- The strongest relationships between field biomass change and satellite data were observed for those sensors having spatial resolutions in the middle of the $0.30-30 \mathrm{~m}$ range (3 m resolution for PlanetScope, $1.5 \mathrm{~m}$ for SPOT-7 and $10 \mathrm{~m}$ for Sentinel-2). Weaker relationships were observed for the very high resolution sensors $(<1.5 \mathrm{~m})$. Insignificant results were found for Landsat data at $30 \mathrm{~m}$ spatial resolution. This suggests that local measurements of canopy variation are possible when the data is neither too detailed (which increases the noise content) or coarse (which smooths the information content);

- We found that there is an optimal window size for detecting forest degradation when extracting textural information. This size slightly varies across the sensors; in this study, the optimal range was found between $9-14 \mathrm{~m}$ in length for a square window, suggesting that local variation in forest canopies is best measured when the window size is of comparable scale to the tree crown diameter.

Future research in the FODEX project will expand this analysis and attempt at reducing the noise content of the biomass maps by fusing multispectral optical information with the remote sensing radar measurements acquired over the study area. Local LiDAR data will also provide a larger sample size, improving the accuracy of the model. The robustness of the developed models will be tested by transferring the biomass change estimates to other regions with varying vegetation and disturbance events.

Author Contributions: Conceptualization, C.A. and E.M.; methodology, C.A and E.M.; software, C.A.; validation, C.A. and E.M.; formal analysis, C.A.; investigation, C.A., I.M., H.C. and B.P.V; resources, S.M. and B.P.V; data curation, A.B, I.M, C.A and H.C.; writing-original draft preparation, C.A.; writing-review and editing, E.M., I.M. and H.C.; visualization, C.A.; supervision, E.M. and M.D.; project administration, E.M.; funding acquisition, E.M. All authors have read and agreed to the published version of the manuscript.

Funding: This research was funded by a European Research Council Starting Grant awarded to Edward Mitchard (The Tropical Forest Degradation Experiment - FODEX: 757526)

Data Availability Statement: Data supporting these results is available at https://doi.org/10.608 4/m9.figshare.19103339.v1 (accessed on 1 February 2022) 
Acknowledgments: We would like to thank La Comunidad Nativa de Bélgica for allowing us to conduct this research on their land, and for offering material and moral support during our permanence in their community. We would like to specially thank the NGO AIDER - Asociación para la Investigación y Desarrollo Integral, for offering their invaluable help with the campaign preparation and for continuously supporting us with the logistics, ensuring the best outcome for our fieldwork. This research would have not been possible without the work of the field assistants. In particular, we would like to thank Roxana Sacatuma Cruz and José Sánchez Tintaya, and the field assistants from Bélgica, Arturo Aspajo López, Leoncio Aspajo Lopez, Luis López Chapiama and Kenny López Batista, for assisting us with the field inventory work, but also for their generous guidance and advice. We also acknowledge the assistance provided with customs and logistics by Prof. Eric Cosio and Dr. Norma Salinas from the Pontificia Universidad Católica del Perú. We finally thank the Regional Government of Madre de Dios for issuing the Authorisation for Scientific Research Purposes on Local Flora outside of natural protected areas with authorisation code $\mathrm{N}^{\circ}$ 17-MAD/AUT-IFL-2019-001.

This paper is dedicated to the memory of our colleague and friend Luis Miguel Álvarez Mayorga, who greatly contributed to the data collection for this study.

Conflicts of Interest: The authors declare no conflict of interest. The funders had no role in the design of the study; in the collection, analyses, or interpretation of data; in the writing of the manuscript, or in the decision to publish the results.

\section{References}

1. Austin, K.G.; González-Roglich, M.; Schaffer-Smith, D.; Schwantes, A.M.; Swenson, J.J. Trends in size of tropical deforestation events signal increasing dominance of industrial-scale drivers. Environmental Research Letters 2017, 12, 054009.

2. Gao, Y.; Skutsch, M.; Paneque-Gálvez, J.; Ghilardi, A. Remote sensing of forest degradation: a review. Environmental Research Letters 2020, 15, 103001.

3. Gatti, L.V.; Basso, L.S.; Miller, J.B.; Gloor, M.; Gatti Domingues, L.; Cassol, H.L.G.; Tejada, G.; Aragão, L.E.O.C.; Nobre, C.; Peters, W.; Marani, L.; Arai, E.; Sanches, A.H.; Corrêa, S.M.; Anderson, L.; Von Randow, C.; Correia, C.S.C.; Crispim, S.P.; Neves, R.A.L. Amazonia as a carbon source linked to deforestation and climate change. Nature 2021, 595, 388-393.

4. Mitchard, E.T.A. The tropical forest carbon cycle and climate change. Nature 2018, 559, 527-534.

5. Nabuurs, G.J.; Ravindranath, N.H.; Paustian, K.; Freibauer, A.; Hohenstein, W.; Makundi, W.; Aalde, H.; Abdelgadir, A.Y.; Khalil, A.S.A.; Barton, J.; Bickel, K.; Bin-Musa, S.; Blain, D.; Boer, R.; Byrne, K.; Cerri, C.; Ciccarese, L.; Choque, D.C.; Duchemin, E.; Dja, L.; Ford-Robertson, J.; Galinski, W.; Germon, J.C.; Ginzo, H.; Gytarsky, M.; Heath, L.; Loustau, D. LUCF sector good practice guidance 2003. Publisher: IPCC.

6. Joshi, N.; Mitchard, E.T.; Woo, N.; Torres, J.; Moll-Rocek, J.; Ehammer, A.; Collins, M.; Jepsen, M.R.; Fensholt, R. Mapping dynamics of deforestation and forest degradation in tropical forests using radar satellite data. Environmental Research Letters 2015, $10,034014$.

7. Houghton, R.A. Carbon emissions and the drivers of deforestation and forest degradation in the tropics. Current Opinion in Environmental Sustainability 2012, 4, 597-603.

8. Hosonuma, N.; Herold, M.; Sy, V.D.; Fries, R.S.D.; Brockhaus, M.; Verchot, L.; Angelsen, A.; Romijn, E. An assessment of deforestation and forest degradation drivers in developing countries. Environmental Research Letters 2012, 7, 044009.

9. Qin, Y.; Xiao, X.; Wigneron, J.P.; Ciais, P.; Brandt, M.; Fan, L.; Li, X.; Crowell, S.; Wu, X.; Doughty, R.; Zhang, Y.; Liu, F.; Sitch, S.; Moore, B. Carbon loss from forest degradation exceeds that from deforestation in the Brazilian Amazon. Nature Climate Change 2021, 11, 442-448.

10. Matricardi, E.A.T.; Skole, D.L.; Costa, O.B.; Pedlowski, M.A.; Samek, J.H.; Miguel, E.P. Long-term forest degradation surpasses deforestation in the Brazilian Amazon. Science 2020, 369, 1378-1382.

11. Windisch, M.G.; Davin, E.L.; Seneviratne, S.I. Prioritizing forestation based on biogeochemical and local biogeophysical impacts. Nature Climate Change 2021, 11, 867-871.

12. Duguma, L.A.; Minang, P.A.; Aynekulu, B.E.; Carsan, S.; Nzyoka, J.; Bah, A.; Jamnadass, R.H. From Tree Planting to Tree Growing: Rethinking Ecosystem Restoration Through Tree. Working Paper, World Agroforestry, 2020.

13. Lewis, S.L.; Wheeler, C.E.; Mitchard, E.T.A.; Koch, A. Restoring natural forests is the best way to remove atmospheric carbon. Nature 2019, 568, 25-28.

14. Moreno-Mateos, D.; Barbier, E.B.; Jones, P.C.; Jones, H.P.; Aronson, J.; López-López, J.A.; McCrackin, M.L.; Meli, P.; Montoya, D.; Rey Benayas, J.M. Anthropogenic ecosystem disturbance and the recovery debt. Nature Communications 2017, 8, 14163.

15. Sze, J.S.; Carrasco, L.R.; Childs, D.; Edwards, D.P. Reduced deforestation and degradation in Indigenous Lands pan-tropically. Nature Sustainability 2021, pp. 1-8.

16. Gregorio, N.; Herbohn, J.; Tripoli, R.; Pasa, A. A Local Initiative to Achieve Global Forest and Landscape Restoration Challenge-Lessons Learned from a Community-Based Forest Restoration Project in Biliran Province, Philippines. Forests 2020, 11, 475 . 
17. Rights and Resources Initiative. A Global Baseline of Carbon Storage in Collective Lands, 2018. Rights and Resources Initiative, Washington, DC. Available online https:/ /rightsandresources.org/wp-content/uploads/2016/10/Toward-a-Global-Baseline-ofCarbon-Storage-in-Collective-Lands-November-2016-RRI-WHRC-WRI-report.pdf.

18. Santika, T.; Meijaard, E.; Budiharta, S.; Law, E.A.; Kusworo, A.; Hutabarat, J.A.; Indrawan, T.P.; Struebig, M.J.; Raharjo, S.; Huda, I.; Sulhani.; Ekaputri, A.D.; Trison, S.; Stigner, M.; Wilson, K.A. Community forest management in Indonesia: Avoided deforestation in the context of anthropogenic and climate complexities. Global Environmental Change 2017, 46, 60-71.

19. Chhatre, A.; Agrawal, A. Trade-offs and synergies between carbon storage and livelihood benefits from forest commons. Proceedings of the National Academy of Sciences 2009, 106, 17667-17670.

20. Fleischman, F.; Basant, S.; Chhatre, A.; Coleman, E.A.; Fischer, H.W.; Gupta, D.; Güneralp, B.; Kashwan, P.; Khatri, D.; Muscarella, R.; Powers, J.S.; Ramprasad, V.; Rana, P.; Solorzano, C.R.; Veldman, J.W. Pitfalls of Tree Planting Show Why We Need PeopleCentered Natural Climate Solutions. BioScience 2020, 70, 947-950.

21. Stephan, B. Bringing discourse to the market: the commodification of avoided deforestation. Environmental Politics 2012, 21, 621-639.

22. McAfee, K. The Contradictory Logic of Global Ecosystem Services Markets. Development and Change 2012, 43, $105-131$.

23. Magessa, K.; Wynne-Jones, S.; Hockley, N. Are policies for decentralised forest governance designed to achieve full devolution? Evidence from Eastern Africa. International Forestry Review 2020, 22, 83-101.

24. Plumb, S.T.; Nielsen, E.A.; Kim, Y.S. Challenges of Opportunity Cost Analysis in Planning REDD+: A Honduran Case Study of Social and Cultural Values Associated with Indigenous Forest Uses. Forests 2012, 3, 244-264.

25. Asiyanbi, A.P.; Arhin, A.A.; Isyaku, U. REDD+ in West Africa: Politics of Design and Implementation in Ghana and Nigeria. Forests 2017, 8, 78 .

26. Bayrak, M.M.; Marafa, L.M. Ten Years of REDD+: A Critical Review of the Impact of REDD+ on Forest-Dependent Communities. Sustainability 2016, 8, 620 .

27. Bassey, N. Stop the Continent Grab and the REDD-ification of Africa. No REDD in Africa Network, 2015.

28. Poudel, M.; Thwaites, R.; Race, D.; Dahal, G.R. Social equity and livelihood implications of REDD+ in rural communities - a case study from Nepal. International Journal of the Commons 2015, 9, 177-208. Number: 1.

29. Nielsen, T.D. The role of discourses in governing forests to combat climate change. International Environmental Agreements: Politics, Law and Economics 2014, 14, 265-280.

30. Johnson, S. Discourse and Practice of REDD+ in Ghana and the Expansion of State Power. Sustainability 2021, $13,11358$.

31. Hansen, M.C.; Potapov, P.V.; Moore, R.; Hancher, M.; Turubanova, S.A.; Tyukavina, A.; Thau, D.; Stehman, S.V.; Goetz, S.J.; Loveland, T.R.; Kommareddy, A.; Egorov, A.; Chini, L.; Justice, C.O.; Townshend, J.R.G. High-Resolution Global Maps of 21st-Century Forest Cover Change. Science 2013, 342, 850-853.

32. Wheeler, D.; Guzder-Williams, B.; Petersen, R.; Thau, D. Rapid MODIS-based detection of tree cover loss. International Journal of Applied Earth Observation and Geoinformation 2018, 69, 78-87.

33. Lu, D. The potential and challenge of remote sensing-based biomass estimation. International Journal of Remote Sensing 2006, 27, 1297-1328.

34. Mlambo, R.; Woodhouse, I.H.; Gerard, F.; Anderson, K. Structure from Motion (SfM) photogrammetry with drone data: a low cost method for monitoring greenhouse gas emissions from forests in developing countries. Forests 2017, 8.

35. McNicol, I.M.; Mitchard, E.T.A.; Aquino, C.; Burt, A.; Carstairs, H.; Dassi, C.; Modinga Dikongo, A.; Disney, M.I. To What Extent Can UAV Photogrammetry Replicate UAV LiDAR to Determine Forest Structure? A Test in Two Contrasting Tropical Forests Journal of Geophysical Research: Biogeosciences 2021, 126, e2021JG006586.

36. Filippelli, S.; Lefsky, M.; Rocca, M. Comparison and integration of lidar and photogrammetric point clouds for mapping pre-fire forest structure. Remote Sensing of Environment 2019.

37. Shimizu, K.; Ota, T.; Mizoue, N. Detecting Forest Changes Using Dense Landsat 8 and Sentinel-1 Time Series Data in Tropical Seasonal Forests. Remote Sensing 2019, 11, 1899.

38. Norway's International Climate and Forest Initiative (NICFI), 2021. https://www.nicfi.no/ (Last accessed on 29/04/2021).

39. Hill, T.C.; Williams, M.; Bloom, A.A.; Mitchard, E.T.A.; Ryan, C.M. Are Inventory Based and Remotely Sensed Above-Ground Biomass Estimates Consistent? PLOS ONE 2013, 8, e74170.

40. Somvanshi, S.S.; Kumari, M. Comparative analysis of different vegetation indices with respect to atmospheric particulate pollution using sentinel data. Applied Computing and Geosciences 2020, 7, 100032.

41. Othman, M.A.; Ash'aari, Z.H.; Aris, A.Z.; Ramli, M.F. Tropical deforestation monitoring using NDVI from MODIS satellite: a case study in Pahang, Malaysia. IOP Conference Series: Earth and Environmental Science 2018, 169, 012047.

42. Huete, A.; Liu, H.; van Leeuwen, W. The use of vegetation indices in forested regions: issues of linearity and saturation. IGARSS'97. 1997 IEEE International Geoscience and Remote Sensing Symposium Proceedings. Remote Sensing - A Scientific Vision for Sustainable Development, 1997, Vol. 4, pp. 1966-1968 vol.4.

43. Lu, D.; Batistella, M. Exploring TM image texture and its relationships with biomass estimation in Rondônia, Brazilian Amazon. Acta Amazonica 2005, 35, 249-257.

44. Sader, S.A.; Waide, R.B.; Lawrence, W.T.; Joyce, A.T. Tropical forest biomass and successional age class relationships to a vegetation index derived from landsat TM data. Remote Sensing of Environment 1989, 28, 143-198. 
45. Fuchs, H.; Magdon, P.; Kleinn, C.; Flessa, H. Estimating aboveground carbon in a catchment of the Siberian forest tundra: Combining satellite imagery and field inventory. Remote Sensing of Environment 2009, 113, 518-531.

46. Nichol, J.E.; Sarker, M.L.R. Improved Biomass Estimation Using the Texture Parameters of Two High-Resolution Optical Sensors. IEEE Transactions on Geoscience and Remote Sensing 2011, 49, 930-948.

47. Zheng, D.; Rademacher, J.; Chen, J.; Crow, T.; Bresee, M.; Le Moine, J.; Ryu, S.R. Estimating aboveground biomass using Landsat 7 ETM+ data across a managed landscape in northern Wisconsin, USA. Remote Sensing of Environment 2004, 93, 402-411.

48. Eckert, S. Improved Forest Biomass and Carbon Estimations Using Texture Measures from WorldView-2 Satellite Data. Remote Sensing 2012, 4, 810-829.

49. Cutler, M.E.J.; Boyd, D.S.; Foody, G.M.; Vetrivel, A. Estimating tropical forest biomass with a combination of SAR image texture and Landsat TM data: An assessment of predictions between regions. ISPRS Journal of Photogrammetry and Remote Sensing 2012, $70,66-77$.

50. Kuplich, T.M.; Curran, P.J.; Atkinson, P.M. Relating SAR image texture to the biomass of regenerating tropical forests. International Journal of Remote Sensing 2005, 26, 4829-4854.

51. Luckman, A.J.; Frery, A.C.; Yanasse, C.C.F.; Groom, G.B. Texture in airborne SAR imagery of tropical forest and its relationship to forest regeneration stage. International Journal of Remote Sensing 1997, 18, 1333-1349.

52. Marceau, D.; Howarth, P.; Dubois, J.; Gratton, D. Evaluation Of The Grey-level Co-occurrence Matrix Method For Land-cover Classification Using Spot Imagery. IEEE Transactions on Geoscience and Remote Sensing 1990, 28, 513-519.

53. De Grandi, G.; Lucas, R.; Kropacek, J. Analysis by Wavelet Frames of Spatial Statistics in SAR Data for Characterizing Structural Properties of Forests. IEEE Transactions on Geoscience and Remote Sensing 2009, 47, 494-507.

54. Kelsey, K.C.; Neff, J.C. Estimates of Aboveground Biomass from Texture Analysis of Landsat Imagery. Remote Sensing 2014, $6,6407-6422$.

55. Lu, D. Aboveground biomass estimation using Landsat TM data in the Brazilian Amazon. International Journal of Remote Sensing 2005, 26, 2509-2525.

56. Tuominen, S.; Pekkarinen, A. Performance of different spectral and textural aerial photograph features in multi-source forest inventory. Remote Sensing of Environment 2005, 94, 256-268.

57. Boyd, D.S.; Danson, F.M. Satellite remote sensing of forest resources: three decades of research development. Progress in Physical Geography: Earth and Environment 2005, 29, 1-26.

58. Puissant, A.; Hirsch, J.; Weber, C. The utility of texture analysis to improve per-pixel classification for high to very high spatial resolution imagery. International Journal of Remote Sensing 2005, 26, 733-745.

59. Franklin, S.E.; Hall, R.J.; Moskal, L.M.; Maudie, A.J.; Lavigne, M.B. Incorporating texture into classification of forest species composition from airborne multispectral images. International Journal of Remote Sensing 2000, 21, 61-79.

60. Saatchi, S.S.; Harris, N.L.; Brown, S.; Lefsky, M.; Mitchard, E.T.A.; Salas, W.; Zutta, B.R.; Buermann, W.; Lewis, S.L.; Hagen, S.; Petrova, S.; White, L.; Silman, M.; Morel, A. Benchmark map of forest carbon stocks in tropical regions across three continents. Proceedings of the National Academy of Sciences 2011, 108, 9899-9904.

61. Diringer, S.E.; Berky, A.J.; Marani, M.; Ortiz, E.J.; Karatum, O.; Plata, D.L.; Pan, W.K.; Hsu-Kim, H. Deforestation Due to Artisanal and Small-Scale Gold Mining Exacerbates Soil and Mercury Mobilization in Madre de Dios, Peru. Environmental Science E Technology 2020, 54, 286-296.

62. Burga Cahuana, C. Participation and Representation: REDD+ in the Native Communities of Belgica and Infierno in the Peruvian Amazon. Master's thesis, University of Illinois at Urbana-Champaign, 2013.

63. Esquivel-Muelbert, A.; Phillips, O.L.; Brienen, R.J.W.; Fauset, S.; Sullivan, M.J.P.; Baker, T.R.; Chao, K.J.; Feldpausch, T.R.; Gloor, E.; Higuchi, N.; Houwing-Duistermaat, J.; Lloyd, J.; Liu, H.; Malhi, Y.; Marimon, B.; Marimon Junior, B.H.; Monteagudo-Mendoza, A.; Poorter, L.; Silveira, M.; Torre, E.V.; Dávila, E.A.; del Aguila Pasquel, J.; Almeida, E.; Loayza, P.A.; Andrade, A.; Aragão, L.E.O.C.; Araujo-Murakami, A.; Arets, E.; Arroyo, L.; Aymard C., G.A.; Baisie, M.; Baraloto, C.; Camargo, P.B.; Barroso, J.; Blanc, L.; Bonal, D.; Bongers, F.; Boot, R.; Brown, F.; Burban, B.; Camargo, J.L.; Castro, W.; Moscoso, V.C.; Chave, J.; Comiskey, J.; Valverde, F.C.; da Costa, A.L.; Cardozo, N.D.; Di Fiore, A.; Dourdain, A.; Erwin, T.; Llampazo, G.F.; Vieira, I.C.G.; Herrera, R.; Honorio Coronado, E.; Huamantupa-Chuquimaco, I.; Jimenez-Rojas, E.; Killeen, T.; Laurance, S.; Laurance, W.; Levesley, A.; Lewis, S.L.; Ladvocat, K.L.L.M.; Lopez-Gonzalez, G.; Lovejoy, T.; Meir, P.; Mendoza, C.; Morandi, P.; Neill, D.; Nogueira Lima, A.J.; Vargas, P.N.; de Oliveira, E.A.; Camacho, N.P.; Pardo, G.; Peacock, J.; Peña-Claros, M.; Peñuela-Mora, M.C.; Pickavance, G.; Pipoly, J.; Pitman, N.; Prieto, A.; Pugh, T.A.M.; Quesada, C.; Ramirez-Angulo, H.; de Almeida Reis, S.M.; Rejou-Machain, M.; Correa, Z.R.; Bayona, L.R.; Rudas, A.; Salomão, R.; Serrano, J.; Espejo, J.S.; Silva, N.; Singh, J.; Stahl, C.; Stropp, J.; Swamy, V.; Talbot, J.; ter Steege, H.; Terborgh, J.; Thomas, R.; Toledo, M.; Torres-Lezama, A.; Gamarra, L.V.; van der Heijden, G.; van der Meer, P.; van der Hout, P.; Martinez, R.V.; Vieira, S.A.; Cayo, J.V.; Vos, V.; Zagt, R.; Zuidema, P.; Galbraith, D. Tree mode of death and mortality risk factors across Amazon forests. Nature Communications 2020, 11, 5515.

64. Adler, R.F.; Huffman, G.J.; Chang, A.; Ferraro, R.; Xie, P.P.; Janowiak, J.; Rudolf, B.; Schneider, U.; Curtis, S.; Bolvin, D.; Gruber, A.; Susskind, J.; Arkin, P.; Nelkin, E. The Version-2 Global Precipitation Climatology Project (GPCP) Monthly Precipitation Analysis (1979-Present). Journal of Hydrometeorology 2003, 4, 1147-1167.

65. Phillips, O.; Baker, T.; Feldpausch, T.; Brienen, R. RAINFOR Field Manual for Plot Establishment and Remeasurement 2001. p. 27.

66. Chave, J.; Coomes, D.; Jansen, S.; Lewis, S.L.; Swenson, N.G.; Zanne, A.E. Towards a worldwide wood economics spectrum. Ecology Letters 2009, 12. 
67. Chave, J.; Réjou-Méchain, M.; Búrquez, A.; Chidumayo, E.; Colgan, M.S.; Delitti, W.B.; Duque, A.; Eid, T.; Fearnside, P.M.; Goodman, R.C.; Henry, M.; Martínez-Yrízar, A.; Mugasha, W.A.; Muller-Landau, H.C.; Mencuccini, M.; Nelson, B.W.; Ngomanda, A.; Nogueira, E.M.; Ortiz-Malavassi, E.; Pélissier, R.; Ploton, P.; Ryan, C.M.; Saldarriaga, J.G.; Vieilledent, G. Improved allometric models to estimate the aboveground biomass of tropical trees. Global Change Biology 2014, 20, 3177-3190.

68. Gonzalez de Tanago, J.; Lau, A.; Bartholomeus, H.; Herold, M.; Avitabile, V.; Raumonen, P.; Martius, C.; Goodman, R.C.; Disney, M.; Manuri, S.; Burt, A.; Calders, K. Estimation of above-ground biomass of large tropical trees with terrestrial LiDAR. Methods in Ecology and Evolution 2018, 9, 223-234.

69. Disney, M.I.; Boni Vicari, M.; Burt, A.; Calders, K.; Lewis, S.L.; Raumonen, P.; Wilkes, P. Weighing trees with lasers: advances, challenges and opportunities. Interface Focus 2018, 8, 20170048.

70. Burt, A.; Boni Vicari, M.; da Costa, A.C.L.; Coughlin, I.; Meir, P.; Rowland, L.; Disney, M. New insights into large tropical tree mass and structure from direct harvest and terrestrial lidar. Royal Society Open Science 2021, 8, 201458.

71. Wilkes, P.; Lau, A.; Disney, M.; Calders, K.; Burt, A.; Gonzalez de Tanago, J.; Bartholomeus, H.; Brede, B.; Herold, M. Data acquisition considerations for Terrestrial Laser Scanning of forest plots. Remote Sensing of Environment 2017, 196, 140-153.

72. Burt, A.; Disney, M.; Calders, K. Extracting individual trees from lidar point clouds using treeseg. Methods in Ecology and Evolution 2019, 10, 438-445.

73. Calders, K.; Newnham, G.; Burt, A.; Murphy, S.; Raumonen, P.; Herold, M.; Culvenor, D.; Avitabile, V.; Disney, M.; Armston, J.; Kaasalainen, M. Nondestructive estimates of above-ground biomass using terrestrial laser scanning. Methods in Ecology and Evolution 2015, 6, 198-208.

74. Raumonen, P.; Kaasalainen, M.; Åkerblom, M.; Kaasalainen, S.; Kaartinen, H.; Vastaranta, M.; Holopainen, M.; Disney, M.; Lewis, P. Fast Automatic Precision Tree Models from Terrestrial Laser Scanner Data. Remote Sensing 2013, 5, 491-520.

75. Planet Labs. Education and Research Program. https://www.planet.com/markets/educationand-research/ (Last accessed on 04/06/2021).

76. DigitalGlobe. Radiometric Use of WorldView-3 Imagery. DigitalGlobe: Longmont, CO, USA, 2016. Available online https://dgcms-uploads-production.s3.amazonaws.com/uploads/document/file/207/Radiometric \_Use \_of \_WorldView-3 \_v2.pdf.

77. Warmerdam, F. The Geospatial Data Abstraction Library. In Open Source Approaches in Spatial Data Handling; Hall, G.B.; Leahy, M.G., Eds.; Advances in Geographic Information Science, Springer: Berlin, Heidelberg, 2008; pp. 87-104.

78. Planet. Planet Imagery Product Specifications. Planet Labs, Inc.: San Francisco, CA, USA, 2021. Available online https://assets.planet.com/docs/Planet_Combined_Imagery_Product_Specs_letter_screen.pdf.

79. Planet Team. Planet Application Program Interface: In Space for Life on Earth. San Francisco, CA, 2017. https://api.planet.com (Last accessed on 25/04/2021).

80. Kotchenova, S.Y.; Vermote, E.F.; Matarrese, R.; Frank J. Klemm, J. Validation of a vector version of the $6 \mathrm{~S}$ radiative transfer code for atmospheric correction of satellite data. Part I: Path radiance. Applied Optics 2006, 45, 6762-6774.

81. Copernicus. Copernicus Open Access Hub, 2020. https://scihub.copernicus.eu/dhus/\#/home (Last accessed on 03/05/2021).

82. U Mueller-Wilm.; O Devignot.; L Pessiot. S2 MPC Sen2Cor configuration and user manual., 2017.

83. Vermote, E.; Roger, J.; Franch, B.; Skakun, S. LaSRC (Land Surface Reflectance Code): Overview, application and validation using MODIS, VIIRS, LANDSAT and Sentinel 2 data's. IGARSS 2018 - 2018 IEEE International Geoscience and Remote Sensing Symposium, 2018, pp. 8173-8176. ISSN: 2153-7003, doi:10.1109/IGARSS.2018.8517622.

84. Vicente-Serrano, S.M.; Pérez-Cabello, F.; Lasanta, T. Assessment of radiometric correction techniques in analyzing vegetation variability and change using time series of Landsat images. Remote Sensing of Environment 2008, 112, 3916-3934.

85. van der Walt, S.; Schönberger, J.L.; Nunez-Iglesias, J.; Boulogne, F.; Warner, J.D.; Yager, N.; Gouillart, E.; Yu, T.; scikit-image contributors. scikit-image: image processing in Python. PeerJ 2014, 2, e453.

86. Sarabandi, P.; Yamazaki, F.; Matsuoka, M.; Kiremidjian, A. Shadow detection and radiometric restoration in satellite high resolution images. IGARSS 2004. 2004 IEEE International Geoscience and Remote Sensing Symposium, 2004, Vol. 6, pp. 3744-3747 vol.6.

87. Townshend, J.R.G.; Justice, C.O. Analysis of the dynamics of African vegetation using the normalized difference vegetation index. International Journal of Remote Sensing 1986, 7, 1435-1445.

88. Lyon, J.G.; Yuan, D.; Lunetta, R.S.; Elvidge, C.D. A change detection experiment using vegetation indices. Photogramm. Eng. Remote Sens 1998, pp. 143-150.

89. Spawn, S.A.; Sullivan, C.C.; Lark, T.J.; Gibbs, H.K. Harmonized global maps of above and belowground biomass carbon density in the year 2010. Scientific Data 2020, 7, 112. Bandiera_abtest: a Cc_license_type: cc_publicdomain Cg_type: Nature Research Journals Number: 1 Primary_atype: Research Publisher: Nature Publishing Group Subject_term: Biogeography;Carbon cycle;Ecosystem services Subject_term_id: biogeography;carbon-cycle;ecosystem-services, doi:10.1038/s41597-020-0444-4. 